\title{
Solution-Processed Metal Oxide Thin Film Nanostructures for Water Splitting Photoelectrodes: A Review
}

\author{
Mi Gyoung Lee ${ }^{\dagger}$, Jong Seong Park ${ }^{\dagger}$, and Ho Won Jang \\ Department of Materials Science and Engineering, Research Institute of Advanced Materials, \\ Seoul National University, Seoul 08826, Korea \\ (Received February 28, 2018; Revised March 22, 2018; Accepted March 26, 2018)
}

\begin{abstract}
Photoelectrochemical (PEC) cells can convert solar energy, the largest potential source of renewable energy, into hydrogen fuel which can be stored, transported, and used on demand. In terms of cost competitiveness compared with fossil fuels, however, both photocatalytic efficiency and cost-effectiveness must be achieved simultaneously. Improvement of cost-effective, scalable, versatile, and eco-friendly fabrication methods has emerged as an urgent mission for PEC cells, and solution-based fabrication methods could be capable of meeting these demands. Herein, we review recent challenges for various nanostructured oxide photoelectrodes fabricated by solution-based processes. Hematite, tungsten oxide, bismuth vanadate, titanium oxide, and copper oxides are the main oxides focused on, and various strategies have been attempted with respect to these photocatalyst materials. The effects of nanostructuring, heterojunctions, and co-catalyst loading on the surface are discussed. Our review introduces notable solution-based processes for water splitting photoelectrodes and gives an outlook on eco-friendly and cost-effective approaches to solar fuel generation and innovative artificial photosynthesis technologies.
\end{abstract}

Key words : Metal oxides, Solution process, Electrodeposition, Hydrothermal, Photoelectrochemical water splitting

\section{Introduction}

\subsection{Needs for Photoelectrochemical Water Splitting}

$\Upsilon$ he depletion of conventional fossil fuels, which are 1 insufficient to meet the energy requirements of an increasing population, is of growing concern for the human race and for socially sustainable development. ${ }^{1-6)}$ Thus it is extremely urgent to search for viable alternative renewable energy sources to replace fossil fuels. Renewable energy sources include solar, wind, wave, and biomass, among which solar energy possesses a theoretical potential of $1.2 \times$ $10^{5} \mathrm{TW}$, more than any other energy source, ${ }^{2)}$ and could in theory easily meet the world's total energy consumption. Solar electricity produced by photovoltaics is still very expensive, difficult to store for long periods, and challenging to distribute over long distances; hence, the efficient and inexpensive conversion of solar energy into chemical energy such as hydrogen is considered a highly desirable way to satisfy long-term energy needs and cost-effectiveness, as shown in Fig. 1(a) and Table 1. ${ }^{7-8)}$ Among envisioned approaches, as shown in Fig. 1(b), photoelectrochemical (PEC) water splitting has attracted considerable interest for storing solar energy in chemical bonds via generation of hydrogen., ${ }^{3,8-13)}$

\footnotetext{
These authors contributed equally to this work.

"Corresponding author: Ho Won Jang

E-mail : hwjang@snu.ac.kr

Tel : +82-2-880-1720 Fax : +82-2-865-9671
}

The unit costs of various energy sources, stated in Table $1,{ }^{7}$ demonstrate that lowering the energy production cost of PEC water splitting should be treated as an urgent mission for satisfying its cost competitiveness compared with fossil fuel. ${ }^{14)}$ The United States Department of Energy (US-DOE) stated in 2011 that the upper limit cost of hydrogen in 2020, which would make this a feasible fuel, would be $2-4$ USD per kg. ${ }^{7)}$ The present cost target for hydrogen generation with PEC water splitting, 5.7 USD per $\mathrm{kg}$, must be further reduced to meet the maximum cost suggested by US-DOE. A similar proposal was announced by the Ministry of Economy, Trade and Industry (METI) of Japan in 2008. METI suggested $40 \mathrm{JPY}$ per $\mathrm{Nm}^{3}$, which is of similar value to the US-DOE proposal, as a hydrogen cost target in 2020. ${ }^{7}$ Table $1,{ }^{7}$ put together by Sayama in 2015 , shows the unit energy costs of various energy resources including current energy resources and renewable sources with high potential. It can be seen that the unit energy cost of current energy resources are usually below 2 JPY per MJ, and the unit energy costs of renewable energy sources are much more expensive than current energy resources. Even though the cost for fossil fuel seems to be on the rise, a further reduction in renewable energy costs is imperative. This is especially true in the case of hydrogen production by PEC water splitting; according to the analysis of Shaner, ${ }^{15)}$ simply attaining very high solar-to-hydrogen conversion efficiency will not guarantee PEC water splitting technology becoming a cost-competitive energy resource. In this regard, much greater advances in system cost reduction are needed. 
(a)

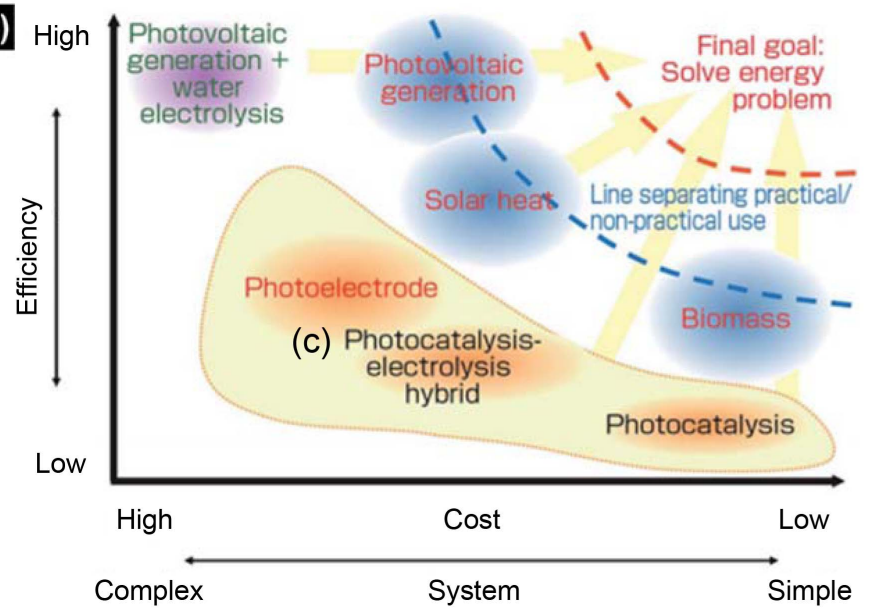

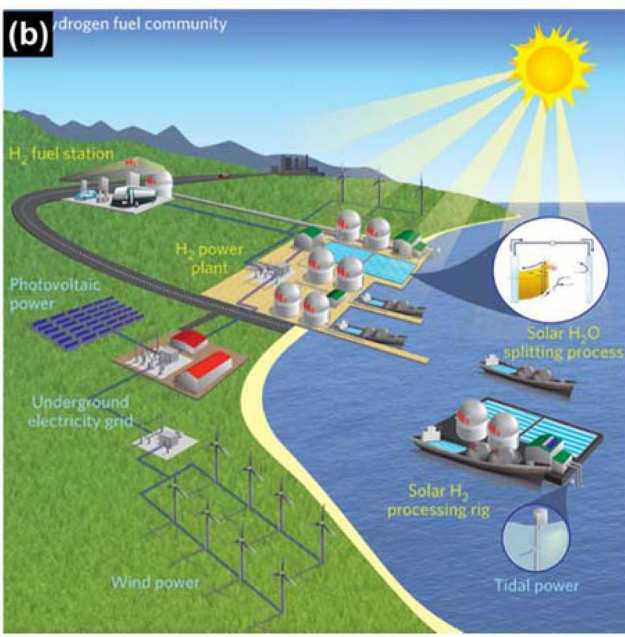

Fig. 1. (a) Technological map showing various approaches to solar energy conversion. Adapted with permission from Ref 7 . (b) Vision of a sustainable hydrogen fuel community based photoelectrochemical water splitting. Adapted with permission from Ref 16.

Table 1. Comparison of Unit Energy Cost. Adapted with Permission from Ref 7

\begin{tabular}{lll}
\hline Energy & Cost/JPY per MJ & Remark \\
\hline Gasoline & $1.8-2.6$ & In 2010 \\
Petroleum & $1.4-1.8$ & In 2010 \\
Liquid natural gas & $0.7-1.7$ & In 2010 \\
Coal & $<0.3$ & In 2010 \\
Fossil fuel (average) & $1.0-1.5$ & In 2010 \\
Hydrogen & 2.4 & Target in 2020 \\
PV & $6.4-10.6$ & In 2013 \\
PV & 1.9 & Target in 2030 \\
PV + water-electrolysis & 10.9 & In 2014 \\
Wind Power & $2.6-6.4$ & In 2010, estimated to be similar in 2030 \\
Biomass-fired power & $4.8-8.9$ & In 2010 \\
Biomass-ethanol & $1.7-4.3$ & Target \\
\hline
\end{tabular}

Figure 1(b), suggested by Tachibana et al. in 2012, ${ }^{16)}$ demonstrates a design for an artificial photosynthesis plant using available renewable energy such as tide, wind, and solar energy for maintenance cost reduction. It would be possible to implement this kind of facility in any seashore or off-shore location where seawater could be pumped and filtered efficiently. However, in order to fulfill large amounts of energy demand with hydrogen fuels, the implementation of large area PEC cells would also be needed. As stated by Maeda et al., ${ }^{17)}$ a solar hydrogen plant with PEC cells (solar energy conversion efficiency of $10 \%$ ) having an area of 25 $\mathrm{km}^{2}$ would produce 570 tons of hydrogen from 5100 tons of water per day. And to supply one-third of the world's energy requirements in 2050, tens of thousands of hydrogen plants would be needed. To satisfy these demands, scalable, and cost-effective fabrication systems for PEC cells would need to be developed and well-established. ${ }^{18)}$

\subsection{Advantages of Solution Process}

From this point of view, solution fabrication methods, such as hydrothermal and electrophoretic deposition, are attractive in terms of their scalability, financial advantages and eco-friendliness. ${ }^{14,19-24)}$ As displayed in Fig. 2, vacuum processes that are currently widely used for many film fabrication methods aggravate global environmental load. Additionally, not only low-pressure fabrication methods but also high-pressure and high-temperature methods contribute environmental load. Without escaping from these types of fabrication method, it is impossible to avoid worsening the environmental footprint. One of the biggest reasons for replacing fossil fuel with renewable energies is to minimize the additional environmental footprint, which makes the advancement of cost-effective and eco-friendly fabrication methods for PEC cells an urgent challenge. Overall, it is obvious that solution based-fabrication methods are a very promising pathway for PEC cell fabrication. 


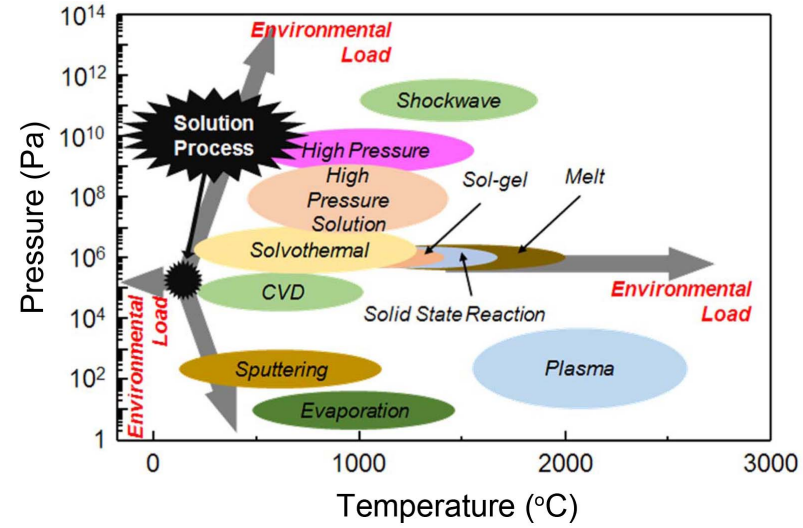

Fig. 2. Needs to proceed to solution processes in the future. The schematic shows energy efficiency improvement of solution processes.

\subsection{Basic Principles of Photoelectrochemical Water Splitting}

The fundamental principle and critical factors of PEC water splitting are displayed in Fig. 3. The interaction of light with a semiconductor as the photoanode generates electron and hole pairs in the semiconductor. The electrons can be excited from the valence band (VB) to the conduction band (CB) of the semiconductor under irradiation by light of suitable wavelengths, leaving holes in the VB..$^{1-2,8,16,25)}$ These electrons and holes can then transfer to the surface of the photoelectrode and initiate hydrogen and oxygen evolution reaction (HER and OER), respectively. Thus, the position of the $\mathrm{CB}$ and VB energy levels of the photoelectrode is crucial to achieve efficient solar water splitting. From a thermodynamic point of view, the minimum of the $\mathrm{CB}$ must be located at a more negative potential than the reduction potential of $\mathrm{H}^{+}$to $\mathrm{H}_{2}(0.41 \mathrm{~V}$ vs. NHE at $\mathrm{pH}$ 7), while the maximum of the VB must exceed the oxidation potential of $\mathrm{H}_{2} \mathrm{O}$ to $\mathrm{O}_{2}\left(0.82 \mathrm{~V}\right.$ vs. NHE). ${ }^{1)}$ In order to drive the water splitting reaction, the photoelectrode must absorb light irra-

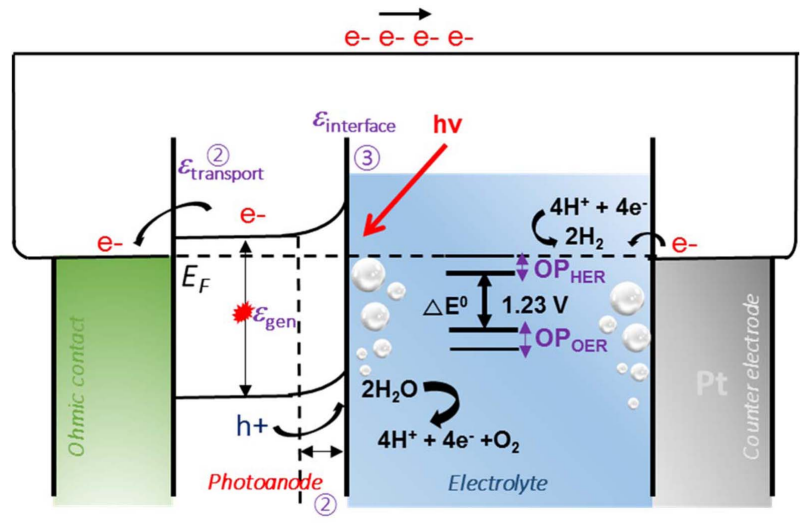

Fig. 3. Principle and critical parameters of photoelectrochemical solar water splitting system. Schematic is described in terms of the photoanode as an n-type semiconductor.

diation to make its electrode potential higher than $1.23 \mathrm{~V}$. In addition, due to energy losses, a kinetic overpotential (OP) is needed to drive the HER and the OER, and thus the band gap energy $\left(E_{\mathrm{g}}\right)$ of the semiconductors as photoelectrodes should lie in the range of 1.5 to $3.1 \mathrm{eV}$, which is within the visible range of the solar spectrum. ${ }^{2)}$ The key criteria for efficient solar water splitting are expressed as the product or the light absorption efficiency; the charge separation efficiency and the injection efficiency of the photogenerated carriers to the reactants; a broad light absorption range; efficient charge transfer from the bulk of the semiconductor to the surface; and rapid consumption of the photogenerated carriers for the surface reaction with minimum overpotential. ${ }^{2,8,26)}$

Another critical factor, which may limit the utilization of several photoelectrode materials, is resistance to photocorrosion, or electrochemical stability. Many non-oxide semiconductors show poor stability due to undesired photocorrosion or anodic photodecomposition, while metal oxide semiconductors are usually more stable over a wide range of

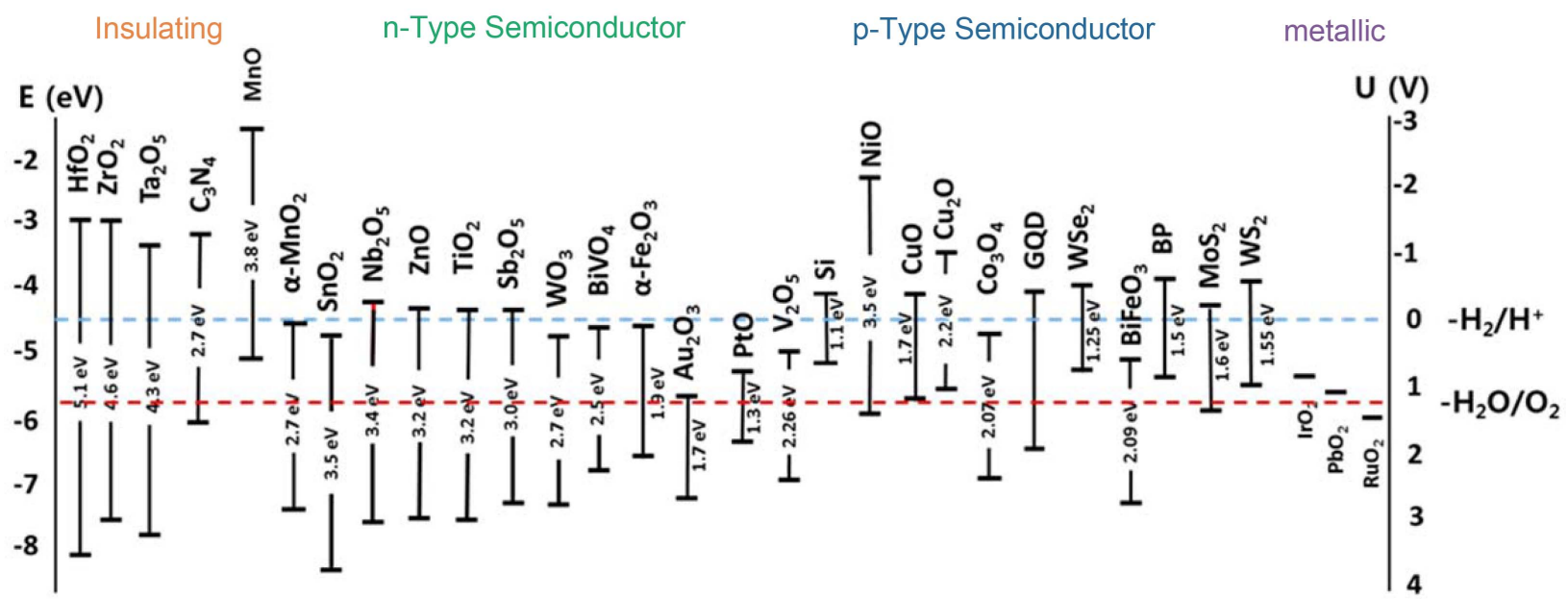

Fig. 4. Band gap energies and band alignments for various PEC water splitting materials. 
$\mathrm{pH}$ values in aqueous environments upon illumination. Metal oxides attract considerable attention due to their excellent chemical stability, suitable band edge positions, low cost, and tunable bandgaps. ${ }^{1,8,11,27)}$ Metal oxides are usually one of the most stable forms of metal compounds in nature and can be easily synthesized. ${ }^{8,28)}$ Moreover, metal oxides have a wide distribution of band gap and band edge positions, as shown in Fig. 4.

To design highly efficient photoelectrodes for water splitting, all of these typical processes such as light absorption, charge separation, transport, and utilization must be comprehensively considered and optimized. The current bottleneck of photoelectrodes is a lower quantum yield than theoretical values, which is strongly affected by severe electron-hole recombination, sluggish photo-generated carrier transport and extraction, surface back reaction, and poor stability. ${ }^{3,26)}$ So far, the efficiency improvement of photoelectrodes is one of the most challenging tasks in solar water splitting systems for practical use. A variety of strategies such as nanostructuring, heterojunction, and co-catalysts have been developed to address the aforementioned drawbacks of metal oxide photoelectrodes for PEC water splitting, and these are summarized in Fig. 5. ${ }^{29)}$ Most of all, compared to their bulk counterparts, nanostructured materials with smaller size and larger interfacial surface area can effectively shorten the diffusion distance for photoexcited charge carriers and facilitate electron-hole separation at the electrode/electrolyte interface, thus improving charge collection and utilization efficiency.,10,16) Therefore, in this review, we focus primarily on nanostructured photoelectrodes with outstanding photoactivity.

This review covers the fundamental aspects of PEC water splitting, focusing primarily on nanostructured metal oxide semiconductors synthesized by solution processes. We report on several studies using nanostructured metal oxides as photoelectrodes for PEC water splitting. The limitations
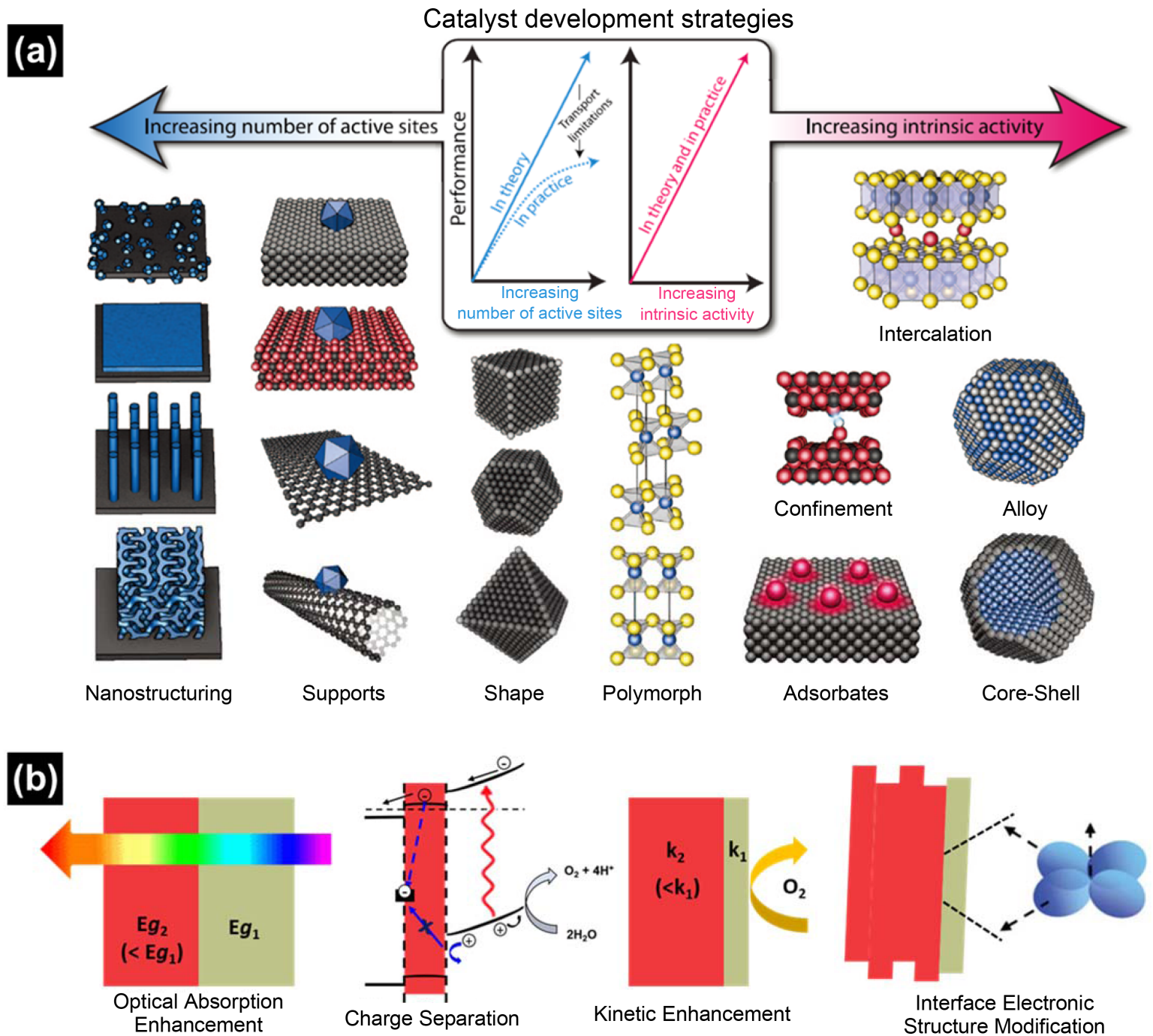

Fig. 5. Catalyst development strategies for efficient solar water splitting system. (a) Schematic of various catalyst development strategies, which aim to increase the number of active sites and/or increase the intrinsic activity of each active site. Adapted with permission from Ref 29. (b) PEC property enhancements in heterogeneous semiconductor photoelectrode. 
of commonly used metal oxide photoanodes and photocathodes for PEC water splitting, as well as the strategies developed to address them, will be thoroughly discussed. Finally, we will provide a brief outlook of the current concepts and future opportunities for metal oxide photoelectrodes in PEC water splitting.

\section{Recent Advances in Solution-based Process for Metal Oxide Photoelectrodes}

Metal oxides, including $\mathrm{Fe}_{2} \mathrm{O}_{3}, \mathrm{BiVO}_{4}, \mathrm{WO}_{3}, \mathrm{TiO}_{2}$, and
$\mathrm{Cu}_{2} \mathrm{O}$, have been extensively explored for PEC water splitting, since they are usually inexpensive, stable, and easily prepared on a large scale for practical applications. To improve the efficiency of metal oxides as photoelectrodes, elemental doping, pairing with various oxygen evolution catalysts (OECs), heterojunctions, and nanostructuring have been studied. Among these, we will focus primarily on diverse nanostructures of metal oxides for water splitting synthesized by solution processes. Table 2 summarizes recent studies of metal oxide photoelectrodes synthesized by solution processes.

Table 2. Recent Reports on Metal Oxide Based Photoelectrodes Synthesized by Solution Process for Solar Water Oxidation

\begin{tabular}{|c|c|c|c|c|c|}
\hline Year & Photoelectrodes & Electrolyte & Performance & Method & Reference \\
\hline 2018 & $\mathrm{WO}_{3}-\mathrm{NRs} / \mathrm{BiVO}_{4}+\mathrm{CoPi}$ & $0.5 \mathrm{M} \mathrm{Na}_{2} \mathrm{SO}_{4}$ & $\begin{array}{c}5.0 \mathrm{~mA} / \mathrm{cm}^{2} \\
\text { (1.23 V vs. RHE) }\end{array}$ & $\begin{array}{l}\text { Hydro-depositing/drop } \\
\text { casting }\end{array}$ & 53 \\
\hline 2017 & $\mathrm{LaFeO}_{3}$ & $0.1 \mathrm{M} \mathrm{NaOH}(\mathrm{pH} 13)$ & $\begin{array}{c}-0.1 \mathrm{~mA} / \mathrm{cm}^{2} \\
(0.73 \mathrm{~V} \text { vs RHE) }\end{array}$ & Electrodeposition & 103 \\
\hline 2017 & $\mathrm{Au} \mathrm{NPs} / \mathrm{BiVO}_{4}$ & $0.5 \mathrm{M} \mathrm{KPi} / 1 \mathrm{M} \mathrm{Na}_{2} \mathrm{SO}_{3}$ & $\begin{array}{c}2.4 \mathrm{~mA} / \mathrm{cm}^{2} \\
(1.23 \mathrm{~V} \text { vs. } \mathrm{RHE})\end{array}$ & $\begin{array}{l}\text { Electrodeposition } \\
\text { /dipping }\end{array}$ & 5 \\
\hline 2017 & $\mathrm{CuO}$ & $0.1 \mathrm{M} \mathrm{KOH} \mathrm{(pH} \mathrm{13)}$ & $\begin{array}{c}-3.5 \mathrm{~mA} / \mathrm{cm}^{2} \\
(0.6 \mathrm{~V} \text { vs RHE) }\end{array}$ & Electrodeposition & 100 \\
\hline 2016 & $\mathrm{BiVO}_{4} / \mathrm{WO}_{3} \mathrm{NRs}$ & $\begin{array}{c}0.5 \mathrm{M} \mathrm{KPi} / 1 \mathrm{M} \mathrm{Na}_{2} \mathrm{SO}_{3} \\
(\mathrm{pH} 7.2)\end{array}$ & $\begin{array}{c}4.55 \mathrm{~mA} / \mathrm{cm}^{2} \\
(1.23 \mathrm{~V} \text { vs. } \mathrm{RHE})\end{array}$ & $\begin{array}{c}\text { GLAD/Pulsed } \\
\text { electrodeposition }\end{array}$ & 3 \\
\hline 2016 & $\mathrm{FeOOH} / \mathrm{Fe}_{2} \mathrm{O}_{3}$ & $1 \mathrm{M} \mathrm{NaOH}(\mathrm{pH} 13.6)$ & $\begin{array}{c}1.21 \mathrm{~mA} / \mathrm{cm}^{2} \\
(1.23 \mathrm{~V} \text { vs. RHE) }\end{array}$ & Solution-based method & 47 \\
\hline 2016 & $\mathrm{Pt} / \mathrm{TiO}_{2} \mathrm{NRs} / \mathrm{p}-\mathrm{Si}$ & $0.5 \mathrm{M} \mathrm{H}_{2} \mathrm{SO}_{4}$ & $\begin{array}{c}40 \mathrm{~mA} / \mathrm{cm}^{2} \\
(0 \mathrm{~V} \text { vs. } \mathrm{RHE})\end{array}$ & $\begin{array}{l}\text { Hydrothermal/ } \\
\text { e-beam evaporation }\end{array}$ & 88 \\
\hline 2016 & $\mathrm{NiFe}-\mathrm{LDH} / \mathrm{Cu}_{2} \mathrm{O}$ & $0.5 \mathrm{M} \mathrm{Na}_{2} \mathrm{SO}_{4}(\mathrm{pH} \mathrm{6.0)}$ & $\begin{array}{c}2.42 \mathrm{~mA} / \mathrm{cm}^{2} \\
(-0.6 \mathrm{~V} \text { vs. } \mathrm{Ag} / \mathrm{AgCl})\end{array}$ & Electrodeposition & 94 \\
\hline 2016 & $\mathrm{Cu}_{2} \mathrm{O} / \mathrm{CuO}$ & $0.5 \mathrm{M} \mathrm{Na}_{2} \mathrm{SO}_{4}(\mathrm{pH} \mathrm{6.0)}$ & $\begin{array}{l}-2.47 \mathrm{~mA} / \mathrm{cm}^{2} \\
(0 \mathrm{~V} \text { vs } \mathrm{RHE})\end{array}$ & r-DPPC deposition & 95 \\
\hline 2015 & $\begin{array}{l}\mathrm{Co}-\mathrm{Pi} / \mathrm{BiVO}_{4} / \mathrm{WO}_{3^{-}} \\
\mathrm{NRs} / \mathrm{ITO} / \mathrm{Pt} / \mathrm{ITO}\end{array}$ & $\begin{array}{c}0.5 \mathrm{M} \mathrm{KPi} / 1 \mathrm{M} \mathrm{Na}_{2} \mathrm{SO}_{3} \\
(\mathrm{pH} 7.2)\end{array}$ & $\begin{array}{c}6.72 \mathrm{~mA} / \mathrm{cm}^{2} \\
(1.23 \mathrm{~V} \text { vs. RHE) }\end{array}$ & $\begin{array}{l}\text { Multi-magnetron GLAD/ } \\
\text { electrodeposition }\end{array}$ & 54 \\
\hline 2014 & $\mathrm{Fe}-\mathrm{NiOOH} / \mathrm{BiVO}_{4}$ & $\begin{array}{c}0.5 \mathrm{M} \mathrm{KPi} / 1 \mathrm{M} \mathrm{Na}_{2} \mathrm{SO}_{3} \\
(\mathrm{pH} 7.2)\end{array}$ & $\begin{array}{c}4.16 \mathrm{~mA} / \mathrm{cm}^{2} \\
(0.6 \mathrm{~V} \text { vs. } \mathrm{RHE})\end{array}$ & $\begin{array}{c}\text { Electrodeposition } \\
\text { /photo electrodeposition }\end{array}$ & 48 \\
\hline 2014 & $\mathrm{CuO}$ & $0.5 \mathrm{M} \mathrm{Na}_{2} \mathrm{SO}_{4}(\mathrm{pH} \mathrm{6.0)}$ & $\begin{array}{c}\sim 1.2 \mathrm{~mA} / \mathrm{cm}^{2} \\
(-0.55 \mathrm{~V} \text { vs. } \mathrm{Ag} / \mathrm{AgCl})\end{array}$ & Electrodeposition & 98 \\
\hline 2013 & $\mathrm{Au} / \mathrm{TiO}_{2} \mathrm{NRs}$ & $1 \mathrm{M} \mathrm{KOH} \mathrm{(pH} \mathrm{13.6)}$ & $\begin{array}{c}2.32 \mathrm{~mA} / \mathrm{cm}^{2} \\
(1.23 \mathrm{~V} \text { vs. RHE) }\end{array}$ & $\begin{array}{l}\text { Hydrothermal/ } \\
\text { photoreduction }\end{array}$ & 93 \\
\hline 2013 & $\mathrm{Co}-\mathrm{Pi} / \mathrm{Pt}: \mathrm{Fe}_{2} \mathrm{O}_{3}$ & $1 \mathrm{M} \mathrm{NaOH}(\mathrm{pH} 13.6)$ & $\begin{array}{c}4.32 \mathrm{~mA} / \mathrm{cm}^{2} \\
(1.23 \mathrm{~V} \text { vs. RHE) }\end{array}$ & Solution-based method & 104 \\
\hline 2012 & $\mathrm{BiVO}_{4}$ & $0.1 \mathrm{M} \mathrm{KPi}(\mathrm{pH} 7.0)$ & $\begin{array}{c}1.17 \mathrm{~mA} / \mathrm{cm}^{2} \\
(0.55 \mathrm{~V} \text { vs. RHE) }\end{array}$ & Electrodeposition & 51 \\
\hline 2012 & $\mathrm{FeOOH} / \mathrm{BiVO}_{4}$ & $\begin{array}{c}0.1 \mathrm{M} \mathrm{KPi} / 0.1 \mathrm{M} \mathrm{Na}_{2} \mathrm{SO}_{3} \\
(\mathrm{pH} 7.0)\end{array}$ & $\begin{array}{c}1.7 \mathrm{~mA} / \mathrm{cm}^{2} \\
(1.2 \mathrm{~V} \text { vs. } \mathrm{RHE})\end{array}$ & $\begin{array}{c}\text { Electrodeposition } \\
\text { /photo electrodeposition }\end{array}$ & 52 \\
\hline 2012 & $\mathrm{CuFeO}_{2}$ & $1 \mathrm{M} \mathrm{NaOH}(\mathrm{pH} 13.6)$ & $\begin{array}{l}0.085 \mathrm{~mA} / \mathrm{cm}^{2} \\
(0.6 \mathrm{~V} \text { vs } \mathrm{RHE})\end{array}$ & Electrodeposition & 101 \\
\hline 2012 & $\mathrm{CuBi}_{2} \mathrm{O}_{4}$ & $\begin{array}{c}\mathrm{N}_{2} \text { degassed } \mathrm{Na}_{2} \mathrm{SO}_{4} \\
(\mathrm{pH} \mathrm{10.8})\end{array}$ & $\begin{array}{c}33 \mu \mathrm{\mu A} / \mathrm{cm}^{2} \\
(0.8 \mathrm{~V} \text { vs. } \mathrm{RHE})\end{array}$ & Electrodeposition & 102 \\
\hline 2012 & Ni-doped $\mathrm{Fe}_{2} \mathrm{O}_{3}$ & $1 \mathrm{M} \mathrm{KOH} \mathrm{(pH} \mathrm{13.6)}$ & $\begin{array}{c}3.3 \mathrm{~mA} / \mathrm{cm}^{2} \\
(0.45 \mathrm{~V} \text { vs. Ag/AgCl})\end{array}$ & Electrodeposition & 105 \\
\hline 2011 & $\mathrm{TiO}_{2}$ nanocrystal & $\begin{array}{c}1: 1 \text { water-methanol } \\
\text { solution }\end{array}$ & 13 days stability & Hydrothermal & 62 \\
\hline 2011 & $\mathrm{TiO}_{2}$ & $1 \mathrm{M} \mathrm{KOH} \mathrm{(pH} \mathrm{13.6)}$ & $\begin{array}{l}0.83 \mathrm{~mA} / \mathrm{cm}^{2} \\
(0.8 \mathrm{~V} \text { vs. } \mathrm{RHE})\end{array}$ & Hydrothermal & 92 \\
\hline
\end{tabular}




\subsection{Photoanodes}

\subsubsection{Hematite $\left(\mathrm{Fe}_{2} \mathrm{O}_{3}\right)$}

Iron is the fourth most common element in the earth, where it is already oxidized into ferrous $(+2)$ or ferric $(+3)$ states. Among the crystal structures of iron oxide, hematite is the most thermodynamically stable form, i.e. the most commonly founded in nature. In consideration of system costs, the cost of materials for photoelectrodes needs to be treated as a serious requirement. Its electronic properties as an n-type semi-conductor make hematite a potentially promising photoanode material. The energy band gap of hematite is usually reported to be in the range of 1.9 to 2.2 $\mathrm{eV}$, corresponding to 650 to $560 \mathrm{~nm}$ of wavelength. ${ }^{30)}$ The absorption of yellow to UV photons that are most abundantly contained in incident photons ${ }^{31}$ is strong for this reason. Coupled with its earth-abundance, non-toxicity, and stability in aqueous solution, its electronic properties as a semiconductor make hematite an attractive material for artificial photosynthesis. Exploration of hematite as a solar energy conversion material was first carried out by Hardee and Bard in 1976. ${ }^{32}$ They fabricated hematite thin films on $\mathrm{Ti}$ and $\mathrm{Pt}$ substrates by chemical vapor deposition. Since that time, continuing studies on hematite have been carried out with various fabrication methods, including solutionbased processes. ${ }^{30,33)}$ Herein, only a few notable trials with nanostructured thin films based on solution fabrication methods will be introduced.

Researchers have tried to generate thin films of hematite with donor doping, ${ }^{34-37)}$ as hematite has a short diffusion length $\left(L_{D}=2-4 \mathrm{~nm}\right)^{37-38)}$ and poor majority carrier conductivity. ${ }^{35,39)}$ An increase of doping concentration in turn reduces the width of a space-charge layer between the photoelectrode and the electrolyte. When assuming classical depletion layer theory, ${ }^{40)}$ only $7 \mathrm{~nm}$ width of depletion layer is generated in the case of $\mathrm{Nb}$ - doped single crystal hematite with a concentration of $5 \times 10^{19} \mathrm{~cm}^{-3} \cdot{ }^{35)}$ However, although dopants were added, the relatively low adsorption coefficient for hematite ${ }^{41,42)}$ straddles carrier separation if hema- tite has a planar structure. Because the adsorption depth for planar hematite is in the range of 120 - $46 \mathrm{~nm}$ for photon wavelengths of $550-450 \mathrm{~nm},{ }^{43)}$ fast recombination of excitons will be promoted in the case of a simple planar thin film. Consequently, overcoming these limitations has always been treated as the major barrier for hematite utilization.

In this regard, a recently reported study suggests adaptation of doping and nanostructuring simultaneously. Sivula et $a l .{ }^{44)}$ reported mesoporous hematite thin films on fluorinedoped tin oxide (FTO) substrate prepared by a solutionbased colloidal method. For preparation of the precursor paste, a solution was synthesized by combining $400 \mathrm{mg}$ of $\mathrm{Fe}_{2} \mathrm{O}_{3}$ nanopowder, with $40 \mu \mathrm{L}$ of a $10 \%$ solution of acetylacetone (Acac) and 1-hexanol using a mortar and pestle. The prepared solution was diluted with $1 \%$ Acac in 2-propanol, and this was well-dispersed in a water-bath $\left(10^{\circ} \mathrm{C}\right)$ by an ultrasonic tip sonicator. Finally, the dispersed solution was concentrated by evaporation and mixed with a $4 \mathrm{wt} \%$ solution of hydroxypropyl cellulose (HPC) in 2-propanol. The prepared precursor paste was coated on FTO substrate by doctor-blade at a thickness of $40 \mu \mathrm{m}$, and then annealed by a two-step process in order to remove the organics. Prior to reaching the set point $\left(700-800^{\circ} \mathrm{C}\right)$, an initial heat treatment was carried out at $400^{\circ} \mathrm{C}$ for $10 \mathrm{~h}$. Fig. 6(a), (b) shows different particle sizes of hematite with respect to the heat treatment temperature. Even though a specimen prepared at $800^{\circ} \mathrm{C}$ has larger particle size than at $700^{\circ} \mathrm{C}$, a much higher photocurrent density was exhibited by the $800^{\circ} \mathrm{C}$ specimen. Analysis by XPS (X-ray photoelectron spectroscopy) and UV-Visabsorption spectroscopy showed that doping of Sn from the FTO substrate occurs, due to the high thermal energy which induces large effects on optical properties and photoactivity. Souza et al. $^{45)}$ also tested the effect of doping and nanostructure simultaneously by fabricating nanostructured hematite thin films using a polymeric precursor spin coating method. Both nanostructure and silicon doping concentration were controlled by the concentration of tetraethyl orthosilicate (TEOS), which has the role of sili-
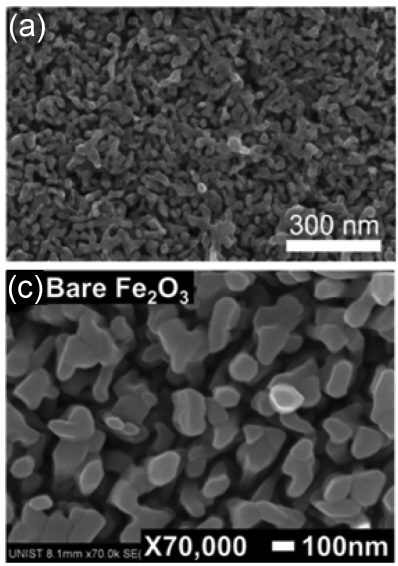
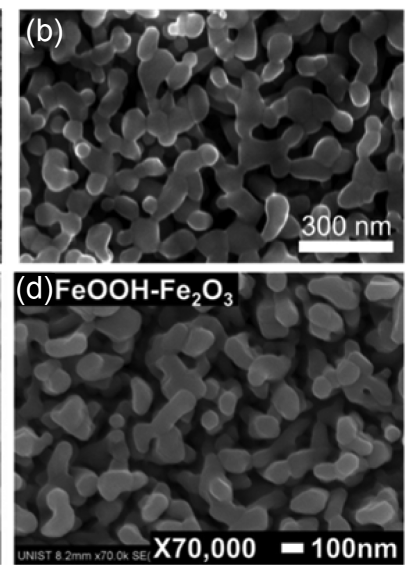
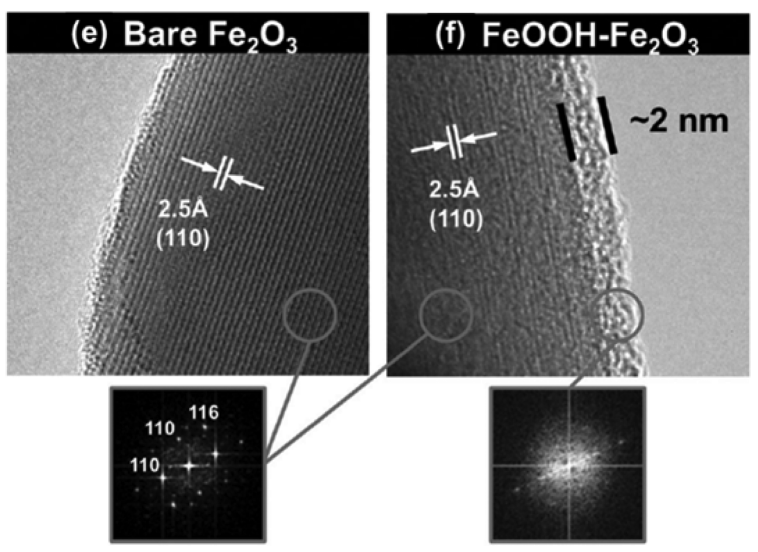

Fig. 6. SEM images of mesoporous hematite fabricated on FTO substrates after annealing: at (a) $700^{\circ} \mathrm{C}$ and (b) $800^{\circ} \mathrm{C}$ for $20 \mathrm{~min}$. Adapted with permission from Ref 44. SEM images and HRTEM images for (c) and (e) bare hematite and (d) and (f) hematite covered with amorphous FeOOH layer with a thickness of about $2 \mathrm{~nm}$. Adapted with permission from Ref 47. 
con precursor. For the polymeric precursor, iron(III) nitrate 9-hydrate and TEOS dissolved in isopropyl alcohol were stirred in citric acid dissolved in DI water and heated in the range of $70-90^{\circ} \mathrm{C}$. Promotion of citrate polymerization was done by stirring and heating after adding ethylene glycol to this solution. Although an optimally-controlled doping concentration of Si exhibited enhanced photocurrent density, it could be seen that the effect of Si doping shows much lower impact compared with Sn doping. For this reason, the effect of doping in hematite relies on the proper type of dopant and enough thermal energy. However, enough thermal energy promotes further growth of crystal size, which highlights the short diffusion length of hematite.

Brillet et $a l .{ }^{46)}$ conquered this phenomenon by encapsulation with silica, whose role is to confine further growth of the hematite crystals. The experimental procedure for preparation of precursor paste was very similar to Sivula et al. ${ }^{45)}$ but titanium isopropoxide was also added for Ti ion doping when the solution was mixed with HPC. First, heat treatment was applied, to remove organic compounds. The encapsulation was then performed by chemical bath deposition. The annealed mesoporous hematite thin films were immersed at $0^{\circ} \mathrm{C}$ in aqueous methanol solution, hexadecyltrimethylammonium chloride, and aqueous ammonia in sequence. The encapsulated hematite films were then annealed at $800^{\circ} \mathrm{C}$ in air. After heat treatment, the silica layer was etched by dilute aqueous $\mathrm{NaOH}(5 \mathrm{M})$. Brillet $e t$ al. demonstrated an adequate fabrication method to restrict further growth of particle size and an enhancement of the doping effect at high temperature. ${ }^{46)}$

Deposition of an $\mathrm{FeOOH}$ (oxygen evolution co-catalyst) overlayer on hematite was recently tested by Kim et al. for further enhancement of the PEC performance. ${ }^{47)}$ Mesoporous hematite thin films were prepared by simply immersing a FTO substrate in a solution containing $0.15 \mathrm{M}$ $\mathrm{FeCl}_{3} \cdot 6 \mathrm{H}_{2} \mathrm{O}$ and placing it in an oven at $100^{\circ} \mathrm{C}$ for $6 \mathrm{~h}$. Fig. 6(f) shows the finely coated $\mathrm{FeOOH}$ layer. Prepared thin films were annealed via a two-step heat treatment: $550^{\circ} \mathrm{C}$ for $1 \mathrm{~h}$ followed by $20 \mathrm{~min}$ annealing at $800^{\circ} \mathrm{C}$. The $\mathrm{FeOOH}$ overlayer was deposited by simply immersing hematite thin films into an aqueous solution containing $0.15 \mathrm{M} \mathrm{FeCl}_{3} \cdot 6 \mathrm{H}_{2} \mathrm{O}$ and $1 \mathrm{M} \mathrm{NaNO}_{3}$ at $100^{\circ} \mathrm{C}$ for $5 \mathrm{~min}$. An increase in surface reaction can be captured by a decrease of onset potential and a doubling of photocurrent density.

\subsubsection{Bismuth Vanadate $\left(\mathrm{BiVO}_{4}\right)$}

Among oxide photoelectrode candidates, $\mathrm{BiVO}_{4}$ has been identified as one of the most promising n-type semiconductor photoanodes for use in solar water oxidation, since it can absorb a substantial portion of the visible spectrum due to its relatively narrow band gap energy $(\sim 2.4 \mathrm{eV})$, and it has a favorable portion of the conduction band very near the

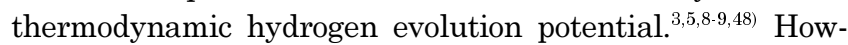
ever, inefficient charge transport and interfacial charge transfer properties are the key limiting factors for $\mathrm{BiVO}_{4}$ photoanodes..$^{3-4,8,48)}$ The presence of a porous nanostructure in the photoelectrodes provides an increased interfacial area between the electrolyte and the film. The formation of nanostructures enables improvement of the water-splitting efficiency, as the photogenerated holes will have to traverse less bulk material to be collected at the solution interface; therefore it has a lower chance of recombining before participating in the electrochemical reaction., ${ }^{4,49)}$ However, increasing the surface area by introducing porosity can also have adverse effects on charge separation and transport, as it can result in an increase in surface states, defect sites, and grain boundaries while decreasing crystallinity. Therefore, the morphologies and surface areas of a photoelectrode should be finely optimized to maximize the overall net positive effect. $^{27)}$

One interesting study by $\mathrm{Xi}$ et $a l{ }^{50)}$ reports that $\mathrm{BiVO}_{4}$ nanoplates synthesized by a hydrothermal method have monoclinic scheelite structures with well-defined facets exposed at the surface. They compared photoactivities of $\mathrm{BiVO}_{4}$ with different morphologies such as nanorods and nanoplates. The $\mathrm{BiVO}_{4}$ nanoplates showed higher photocurrent density than nanorods due to active surface structures of the $\mathrm{BiVO}_{4}$ nanoplates. This study indicates that designing nanostructures with appropriate surface facets is a feasible approach for the improvement of photoactivity.

$\mathrm{BiVO}_{4}$ has also been prepared by a new cathodic electrodeposition method, as demonstrated by McDonald, Choi et $a l{ }^{51-52)}$ A polycrystalline BiOI electrode, composed of extremely thin $2 \mathrm{D}$ plates, allowed for the preparation of porous $\mathrm{BiVO}_{4}$ photoanodes using a simple chemical and thermal treatment. The resulting $\mathrm{BiVO}_{4}$ with high porosity showed outstanding PEC efficiency. On the basis of these results, Kim and $\mathrm{Choi}^{48)}$ modified a previous synthesis developed by McDonald and Choi. ${ }^{51)}$ It is possible to facilitate the production of nanoporous $\mathrm{BiVO}_{4}$, as displayed in Fig. 7(a)-(f), which is composed of much smaller particles, achieving an enlarged surface area. ${ }^{48)}$ The major change was the solution used as the source for conversion of $\mathrm{BiOI}$ to $\mathrm{BiVO}_{4}$. They observed that the surface of BiOI film is highly hydrophobic; thus the aqueous vanadium solution used in the study by McDonald and Choi could not easily penetrate into the $\mathrm{BiVO}_{4}$ films. As a result, the conversion of $\mathrm{BiOI}$ to $\mathrm{BiVO}_{4}$ was initiated only at the top of the film surface, and the grains of $\mathrm{BiVO}_{4}$ grew toward the bottom of the film by slow solid-state diffusion, resulting in the formation of large particles of $\mathrm{BiVO}_{4}$ and no porosity in that direction, limiting the surface area. When the aqueous vanadium solution was replaced by a more hydrophobic DMSO solution containing vanadyl acetylacetonate as the vanadium source, the solution could easily penetrate the entire BiOI film. Therefore, upon heating, multiple nuclei could form, even within a single BiOI sheet, resulting in the formation of smaller particles, which considerably increased the porosity and the surface area. This research proposed a novel technique of electrochemical deposition and demonstrated that nanoporous morphology with high surface area effectively suppresses carrier recombination without additional doping. 

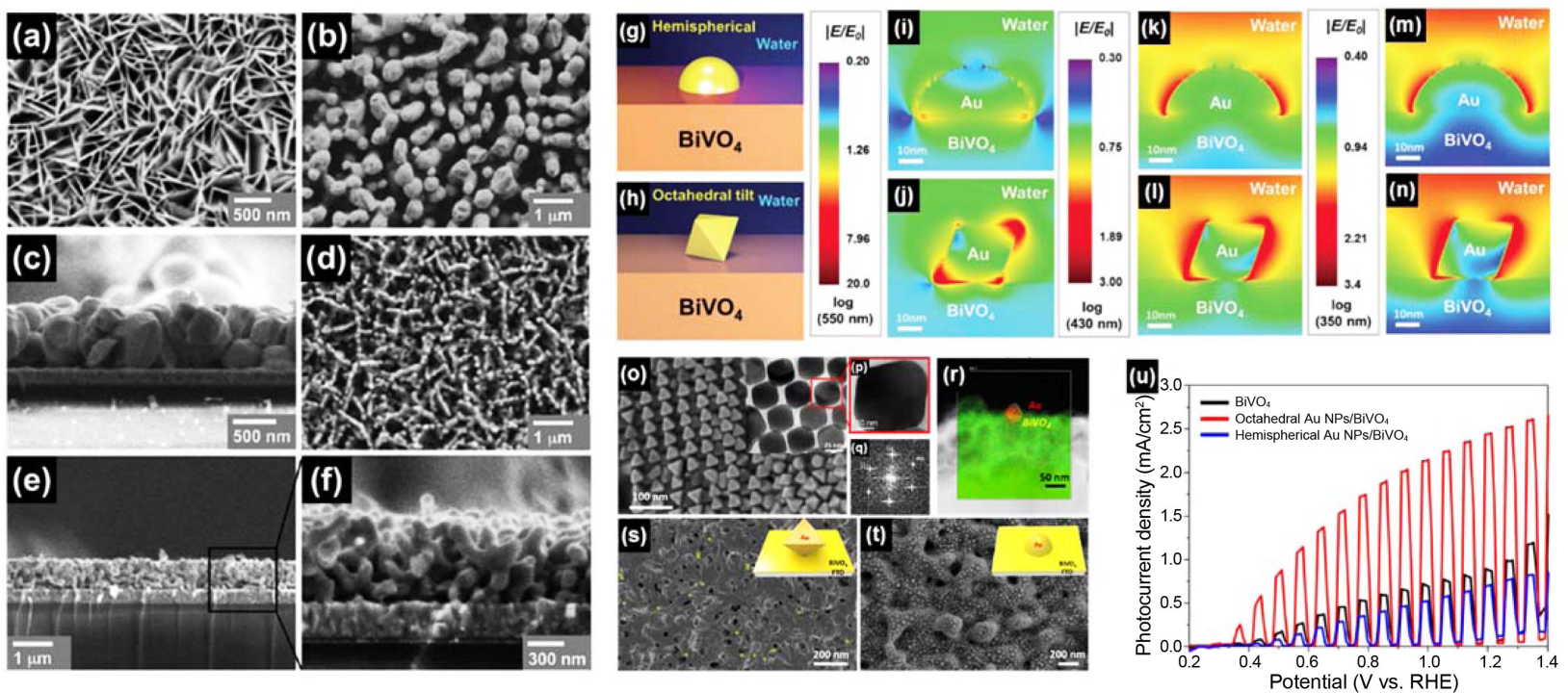

Fig. 7. (a) SEM images for nanoporous (a) BiOI films. (b), (c) Top view and cross-section view of $\mathrm{BiVO}_{4}$ film fabricated by $\mathrm{NH}_{4} \mathrm{OH} / \mathrm{V}_{2} \mathrm{O}_{5}$ and (d)-(f) top view and cross-section view of $\mathrm{BiVO}_{4}$ film fabricated by DMSO/VO(acac) $)_{2}$. Adapted with permission from Ref 48. (g)-(n) Schematic representation of finite-difference time-domain (FDTD) configurations for hemispherical and octahedral Au NPs on $\mathrm{BiVO}_{4}$ film under different wavelength of photon, respectively. (o) SEM, (p) TEM images and (q) FFT pattern of octahedral Au NPs and (r) EDS result of octahedral $\mathrm{NPs}_{\text {on }} \mathrm{BiVO}_{4}$ film by mapping. False color SEM image of (s) octahedral Au NPs on $\mathrm{BiVO}_{4}$ film and (t) hemispherical Au NPs on $\mathrm{BiVO}_{4}$ film. (u) LSV curve of each $\mathrm{BiVO}_{4}$ film. Adapted with permission from Ref 5 .

Another approach to improve absorbance and charge separation efficiency of $\mathrm{BiVO}_{4}$ is shown in Fig. 7(g)-(u). Lee et $a l .{ }^{5)}$ first introduced shape-controlled gold nanoparticles $(\mathrm{Au}$ $\mathrm{NPs}$ ) as plasmonic NPs on $\mathrm{BiVO}_{4}$ thin film synthesized by pulsed electrodeposition. They reported shape-controlled Au NPs with optimum coverage that significantly promote the photoactivity of $\mathrm{BiVO}_{4}$ in over-band gap photon energy, rather than sub-band gap photon energy. Well-defined octahedral Au NPs significantly increased photocurrent density of $\mathrm{BiVO}_{4}$ about 3-fold, while hemispherical Au NPs reduced it, since largely-enhanced localized surface plasmon resonance electric fields (LSPR-EFs) are only observed with octahedral Au NPs. Finite-domain time-difference (FDTD) simulation also validated intensified LSPR-EFs in the entire UV-vis region from octahedral Au NPs, compared to hemispherical $\mathrm{Au}$ NPs, indicating that control of the shape of plasmonic Au NPs is the key to achieving high PEC efficiency.

\subsubsection{Tungsten oxide $\left(\mathrm{WO}_{3}\right)$}

In addition to homogeneous $\mathrm{BiVO}_{4}$, the formation of type II heterojunctions has proven to be effective to facilitate the separation of photo-induced electron-hole pairs, enlarge the interfacial area, and maximize light absorption. ${ }^{3)}$ The combination of $\mathrm{BiVO}_{4}$ and $\mathrm{WO}_{3}$ to form a type II heterojunction not only facilitates charge separation, but also expands the light absorption capability of the composite photoelectrode. ${ }^{3,11,26)}$

Jin et al. first designed a $\mathrm{WO}_{3}$ thin film consisting of yolkshell structured nanoparticles via a solution process without the use of vacuum deposition, as shown in Fig. 8(a)-(f). ${ }^{53)}$
A thin $\mathrm{BiVO}_{4}$ layer with a smaller band gap was coated onto the surface of and inside the $\mathrm{WO}_{3}$ shells, providing a rationally-designed inner space between the particles and the shell for better electrolyte accessibility. The yolk-shellshaped PEC photoanode not only induces efficient light absorption but also plays an important role in electron collection from $\mathrm{BiVO}_{4}$ due to an enlarged contact area. The photocurrent density of the yolk-shell $\left(\mathrm{Y}-\mathrm{WO}_{3} / \mathrm{BiVO}_{4} / \mathrm{OER}\right)$ photoanode achieved its highest value of $5.0 \mathrm{~mA} / \mathrm{cm}^{2}$ at 1.23 V vs. RHE.

Lee et $a l .^{3)}$ reported highly ordered one-dimensional $\mathrm{WO}_{3}$ nanorods by changing their porosity and aspect ratio, and depositing stoichiometric $\mathrm{BiVO}_{4}$ on the surface of the $\mathrm{WO}_{3}$ nanorods by pulsed electrodeposition. The notable point of this research is that cross-sectional transmission electron microscopy shows dot-like $\mathrm{BiVO}_{4}$ well coated on the entire surface of the $\mathrm{WO}_{3}$ nanorods. $\mathrm{BiVO}_{4} / \mathrm{WO}_{3}$ type II heterojunction anodes can lead to a high photocurrent density of 4.55 $\mathrm{mA} / \mathrm{cm}^{2}$ and an incident photon-to-current conversion efficiency of $80 \%$ at $1.23 \mathrm{~V}$ versus a reversible hydrogen electrode without additional catalyst.

Pihosh et al. ${ }^{54)}$ demonstrated this concept with a $\mathrm{WO}_{3} /$ $\mathrm{BiVO}_{4}+\mathrm{CoPi}$ core-shell nanostructured photoanode that achieves near theoretical water splitting efficiency, as shown in Fig. 8(h)-(k). This study combines $\mathrm{BiVO}_{4}$ with more conductive $\mathrm{WO}_{3}$ nanorods in the form of a core-shell heterojunction, where the $\mathrm{BiVO}_{4}$ absorber layer is thinner than the carrier diffusion length, while its optical thickness is re-established by light trapping in high aspect ratio nanostructures. Their photoanode demonstrates an ultimate water splitting photocurrent of $6.72 \mathrm{~mA} / \mathrm{cm}^{2}$ under 1 sun 

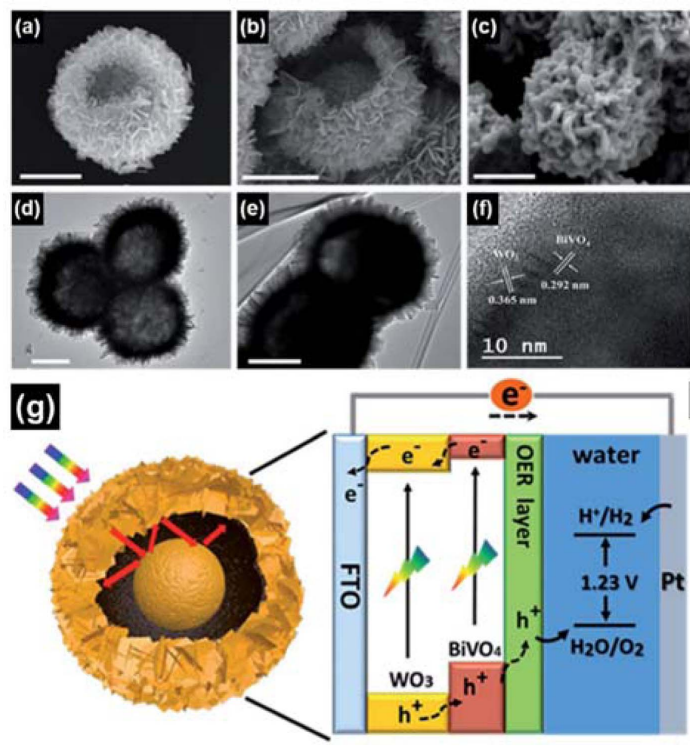

(1)
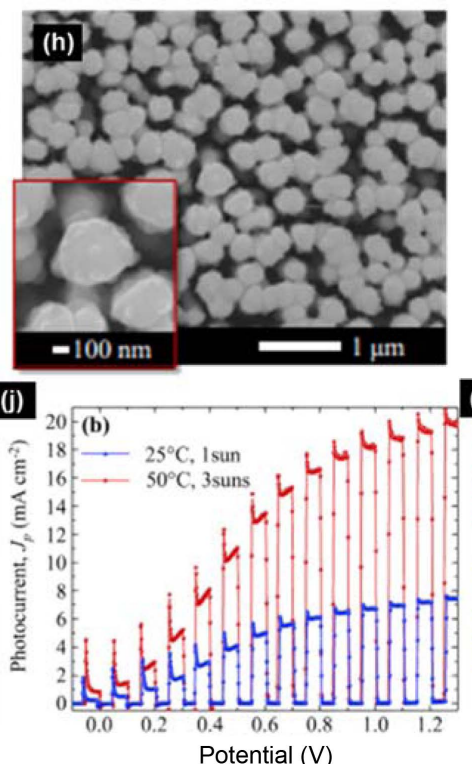

(k)

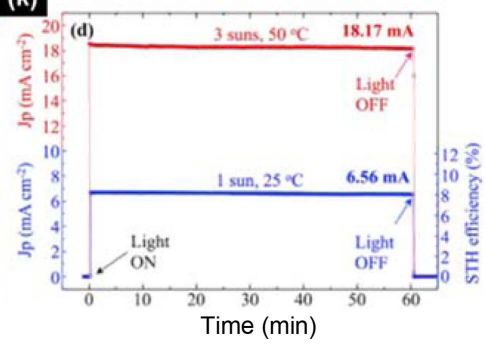

Fig. 8. SEM and TEM images of (a), (d) hollow $\mathrm{WO}_{3}$, (b), (e) yolk-shell $\mathrm{WO}_{3}$ and (c), (f) yolk-shell $\mathrm{WO}_{3} / \mathrm{BiVO}_{4}$ heterojunctions, respectively. (g) Schematic representation of the yolk-shell $\mathrm{WO}_{3} / \mathrm{BiVO}_{4}$ photoanode and expected energy band diagram. Adapted with permission from Ref 53. (h), (i) Top and cross-sectional SEM images of $\mathrm{BiVO}_{4}$ coated on $\mathrm{WO}_{3}$ nanorods. (j) Linear sweep voltammograms for $\mathrm{WO}_{3}-\mathrm{NRs} / \mathrm{BiVO}_{4}+\mathrm{CoPi}$ photoanode measured under chopped light at 1 sun, $25^{\circ} \mathrm{C}$ and at 3 suns, $50^{\circ} \mathrm{C}$. (k) $\mathrm{J}_{p}$-t profiles measured for the PEC-PV tandem at 1 sun, $25^{\circ} \mathrm{C}$ (blue) and 3 suns, $50^{\circ} \mathrm{C}$ (red). Adapted with permission from Ref 54.

illumination at $1.23 \mathrm{~V}$ vs. RHE, which corresponds to 90\% of the theoretically possible value for $\mathrm{BiVO}_{4}$.

\subsubsection{Titanium dioxide $\left(\mathrm{TiO}_{2}\right)$}

Titanium dioxide $\left(\mathrm{TiO}_{2}\right)$ has been favored in many industrial fields for its excellent thermodynamic stability and chemical resistance. ${ }^{55-59)}$ In the case of photocatalytic applications, the discovery of photocatalytic phenomena of $\mathrm{TiO}_{2}$ by Fujishima and Honda in $1972^{60)}$ demonstrated the potential for new applicable areas, i.e. photovoltaics and photocatalysts. Since then, considerable efforts have been made to make $\mathrm{TiO}_{2}$ a promising material for photocatalysis, ${ }^{55,61-65)}$ and today $\mathrm{TiO}_{2}$ is considered one of the potential candidates to play an important role in solving environmental and pollution problems as a photocatalyst. Following the innovative work of Fujishima and Honda, several synthetic methods including sol-gel, ${ }^{66-70)}$ chemical vapor deposition, ${ }^{\text {71-74) }}$ physical vapor deposition, ${ }^{75-77)}$ and others ${ }^{78-81)}$ have been adapted to synthesize $\mathrm{TiO}_{2}$ photocatalysts. But most of these cases show a lower photocurrent density than other photoanodes because of a higher resistance and larger band gap (3.0 - 3.2 $\mathrm{eV})$ for $\mathrm{TiO}_{2}{ }^{82)}$ Consequently, these disadvantages would need to be overcome in order to fabricate stable and efficient $\mathrm{TiO}_{2}$ photoanodes. Several strategies have been proposed to maximize the potential of $\mathrm{TiO}_{2}$ as a photoanode, and these will be further discussed here.

One approach to overcome the limit of $\mathrm{TiO}_{2}$ photocatalysts is reinforcement of photon absorption and reaction with electrolytes by increasing surface area to volume ratio, ${ }^{83)}$ and formation of nanostructure is always a good choice to maximize the surface area of films. Some researchers have synthesized $\mathrm{TiO}_{2}$ nanostructure arrays by coating on different nanostructured templates such as anodic alumina membrane (AAM) and $\mathrm{ZnO}$.

In 2003, Lin et al ${ }^{84)}$ fabricated $\mathrm{TiO}_{2}$ nanowire arrays by electrophoretic deposition into the pores of an AAM. Colloidal suspensions for electrophoretic deposition of $\mathrm{TiO}_{2}$ were synthesized by dissolving titanium tetraisopropoxide (TTIP) in ethanol and mixing with glacial acetic acid solution and the addition of nitric acid to adjust the $\mathrm{pH}$ to 2 - 3. An AAM with an $\mathrm{Au}$ substrate attached to $\mathrm{Cu}$ foil was used as a cathode, and platinum was used as an anode. The deposition condition for the $\mathrm{TiO}_{2}$ coating into the pores of the AAM was a voltage of $2-5 \mathrm{~V}$ and fabricated films were annealed at $500^{\circ} \mathrm{C}$ for $24 \mathrm{~h}$. Isolated $\mathrm{TiO}_{2}$ nanowires could be obtained after dissolving the AAM templates in a $5 \mathrm{wt} \% \mathrm{NaOH}$ solution. The length of the nanowires was dependent on the length of the AAM pores.

$\mathrm{TiO}_{2}$ nanotubes can be fabricated using the sol-gel method and AAM templates. Lee et al. in $2004^{85)}$ dipped an AAM template into a TTIP solution prepared by mixing TTIP with 2-propanol and 2,4-pentanedione, and the sol-coated template was placed under vacuum until the entire volume of the solution was pulled through the AAM. The AAM was hydrolyzed by water vapor over $\mathrm{HCl}$ solution for $24 \mathrm{~h}$, airdried at room temperature, and then calcined at $400^{\circ} \mathrm{C}$ for 2 $\mathrm{h}$ and cooled to room temperature at a cooling rate of $2^{\circ} \mathrm{C} / \mathrm{h}$. Pure $\mathrm{TiO}_{2}$ nanotubes were obtained after the AAM was dissolved in $6 \mathrm{M} \mathrm{NaOH}$ for several min. $\mathrm{TiO}_{2}$ nanotubes could also be obtained by a chemical bath deposition method 
using AAM. Reported by Liu et al.. ${ }^{86)} \mathrm{TiO}_{2}$ nanotubes could be synthesized by simply submerging AAM template in dilute $\mathrm{TiF}_{4}$ at $\mathrm{pH} 2.1$ and $60^{\circ} \mathrm{C}$ for $12-48 \mathrm{~h}$.

Not only AAM, but also a $\mathrm{ZnO}$ nanorod array on glass substrate could be used as a $\mathrm{TiO}_{2}$ nanotube template. Similarly, $\mathrm{TiO}_{2}$ nanotube arrays could be obtained by etching $\mathrm{ZnO}$ in a $\mathrm{ZnO}$ nanorod template coated with $\mathrm{TiO}_{2}$ by a dip-coating method. ${ }^{87)}$ Dilute $\mathrm{HCl}$ was used as an etchant for the $\mathrm{ZnO}$ nanorods and, due to the structure of the $\mathrm{ZnO}$ building unit, the $\mathrm{TiO}_{2}$ nanotubes had pores with a hexagonal shape.

In order to make $\mathrm{TiO}_{2}$ films as photoelectrodes, it is necessary to generate a junction with a conductive substrate. However, a difference of refractive index between $\mathrm{TiO}_{2}$ and the substrate induces a reflection of incident light which reduces light absorption. ${ }^{88)}$ To overcome this phenomenon, some researchers adapted the characteristics of a rutile $\mathrm{TiO}_{2}$ growth unit. As the crystal planes of $\mathrm{TiO}_{2}$ have quite different surface energies, rutile $\mathrm{TiO}_{2}$ shows preferential crystal growth when synthesized by a hydrothermal process. ${ }^{56,89-91)}$ Using this method, fabrication of a branched nanorod structure has been tried. Cho et al. ${ }^{92)}$ fabricated branched nanorod $\mathrm{TiO}_{2}$ films on a FTO substrate by a twostep synthesis. First, $\mathrm{TiO}_{2}$ nanorods were grown hydrothermally on $\mathrm{TiO}_{2}$-coated FTO substrate. Tetrabutyl titanate (TBT), $25 \mathrm{~mL}$ of deionized (DI) water, and $25 \mathrm{~mL}$ of concen- trated $\mathrm{HCl}$ were stirred to create a hydrothermal solution. The obtained $\mathrm{TiO}_{2}$ nanorods films were annealed at $450^{\circ} \mathrm{C}$ for $1 \mathrm{~h}$ in air, and seed nanoparticles for $\mathrm{TiO}_{2}$ branches were deposited by a dip-coating method using the $\mathrm{TiO}_{2}$ polymeric solution. The seeded nanorods films were immersed in an aqueous solution consisting of $10 \mathrm{~mL}$ of DI water, $0-0.5 \mathrm{~mL}$ of $\mathrm{HCl}$, and $0.1 \mathrm{~mL}$ of $\mathrm{TiCl}_{3}$ solution and kept at $80^{\circ} \mathrm{C}$ for 1 2 h. Finally, branched nanorod films were obtained by washing with ethanol and annealing at $450^{\circ} \mathrm{C}$ for $1 \mathrm{~h}$ in air. The obtained nanorods and branched nanorods showed much lower reflectance in the UV region compared with porous nanoparticles because of a change in film density from bottom to top and scattering of incident light. ${ }^{88)}$

Such examples for controlling $\mathrm{TiO}_{2}$ nanostructure have contributed to enormous advances over simple planar thin films, but still further enhancements are needed before $\mathrm{TiO}_{2}$ photoanodes can be commercialized. Based on the belief that research on single $\mathrm{TiO}_{2}$ structures has reached its theoretical upper limit, co-catalyst attached $\mathrm{TiO}_{2}$ photoanodes have been examined recently. Among these, the Au nanoparticle-coated $\mathrm{TiO}_{2}$ branched nanorod structure, reported by $\mathrm{Su}$ et al., ${ }^{93)}$ shows outstanding results. A schematic of the experimental procedure for preparing these nanorods is illustrated in Fig. 9. Similar to the above case, $\mathrm{TiO}_{2}$ nanorods were hydrothermally synthesized on FTO with a
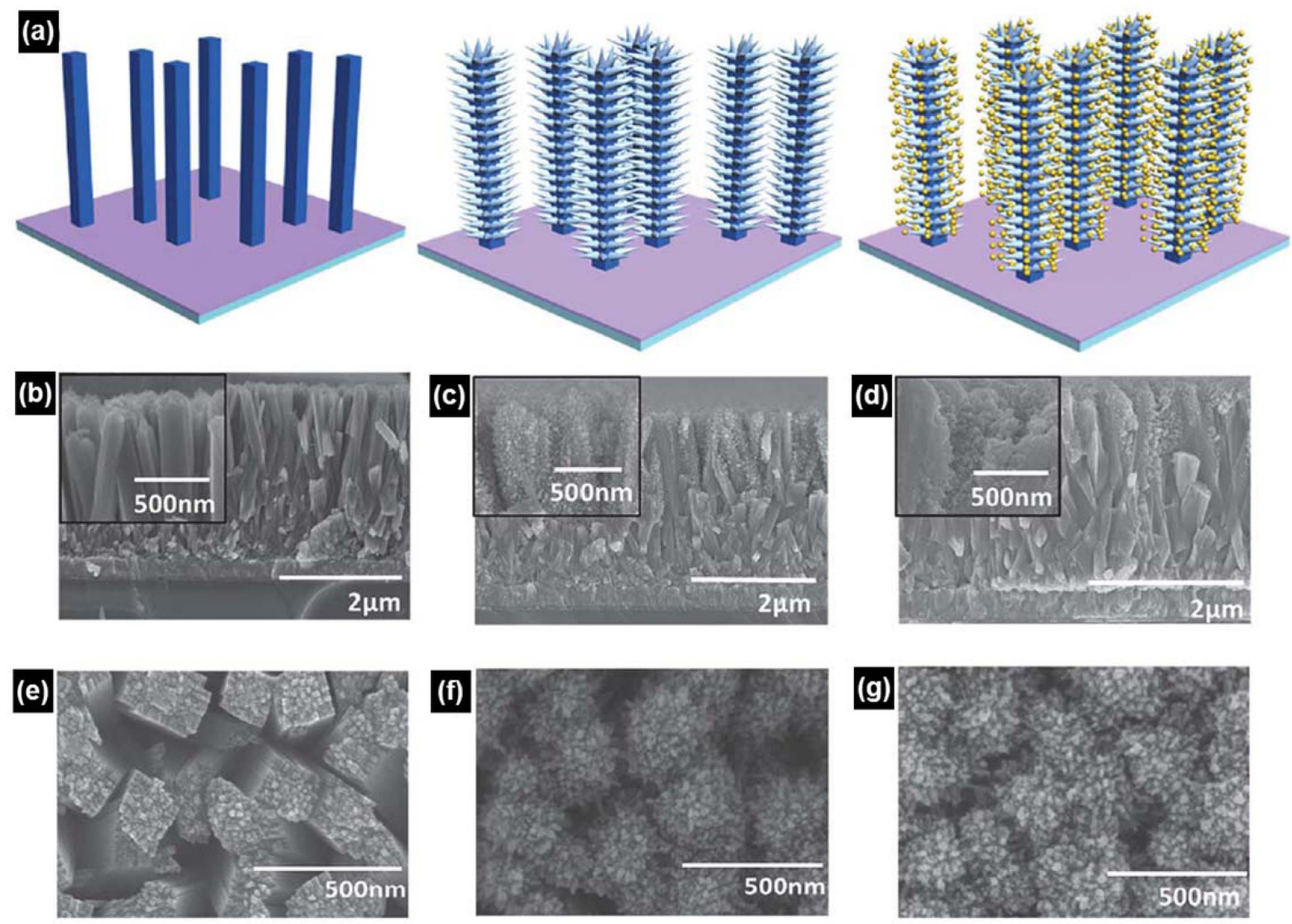

Fig. 9. (a) Schematic representation of the synthesis steps of $\mathrm{Au}$ coated $\mathrm{TiO}_{2}$ branched nanorods (BNRs). Scanning electron micrographs of (b and e) $\mathrm{TiO}_{2} \mathrm{NRs}$, (c and f) $\mathrm{TiO}_{2} \mathrm{BNRs}$ and (d and g) Au coated $\mathrm{TiO}_{2}$ BNRs, respectively. Adapted with permission from Ref 93. 

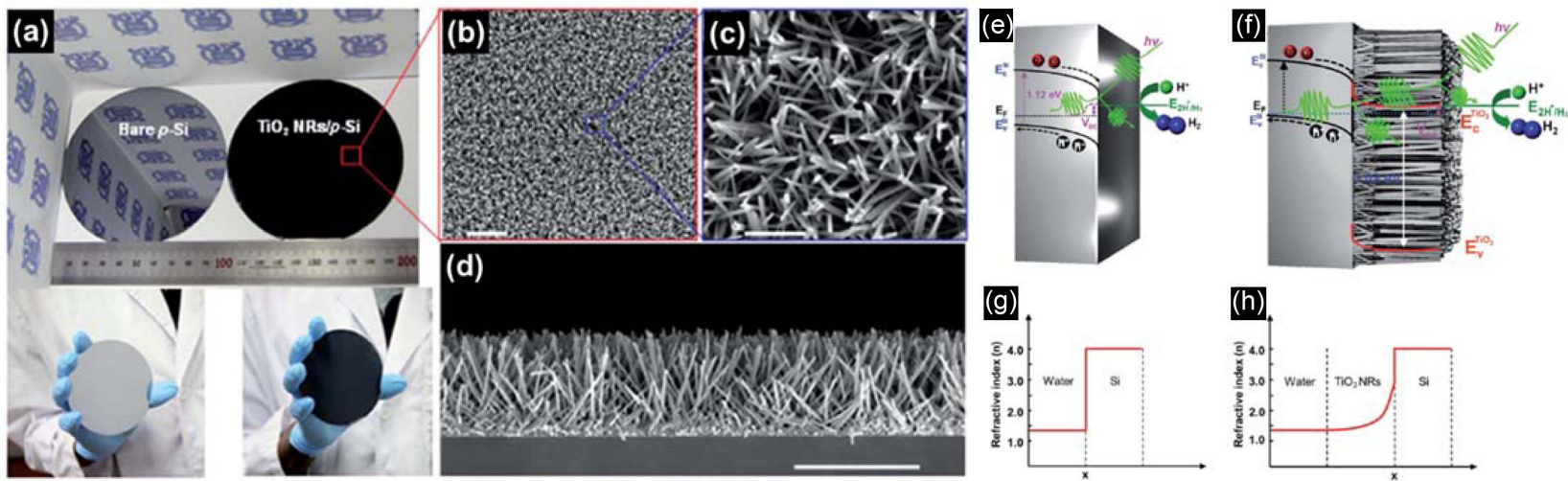

Fig. 10. (a) Optical image of bare p-Si (left) and hydrothermally grown $\mathrm{TiO}_{2} \mathrm{NRs}$ on p-Si (right). SEM images of corresponding $\mathrm{TiO}_{2}$ NRs with (b) and (c) different magnification in top view and (d) cross-section view. Schematic representation of photoelectrodes and corresponding energy band diagrams under irradiation. Possible assumption of light attenuation for (g) electrolyte/p-Si and (h) electrolyte/ $\mathrm{TiO}_{2} \mathrm{NRs} / \mathrm{p}-\mathrm{Si}$ system. Adapted with permission from Ref 88.

solution composed of $30 \mathrm{~mL}$ of DI water, $30 \mathrm{~mL}$ of concentrated $\mathrm{HCl}, 1 \mathrm{~mL}$ of TBT and $5 \mathrm{~mL}$ of $5 \mathrm{M} \mathrm{NaCl}$. Hydrothermally prepared $\mathrm{TiO}_{2}$ nanorods were immersed in $0.2 \mathrm{M}$ $\mathrm{TiCl}_{4}$ at room temperature for $18 \mathrm{~h}$ and then rinsed with absolute ethanol. Specimens were annealed at $450^{\circ} \mathrm{C}$ for 30 min. The fabricated $\mathrm{TiO}_{2}$ branched nanorods were immersed in $0.3 \mathrm{mM} \mathrm{HAuCl}_{4}$, dispersed in DI water, and irradiated with a $300 \mathrm{~W}$ Xe lamp for $6 \mathrm{~h}$ to coat Au nanoparticles on $\mathrm{TiO}_{2}$ surfaces. The much higher photocurrent density shown in this study demonstrates that both strategies, i.e. increasing surface area and enhancing surface reaction by a co-catalyst, can be successfully adopted at the same time.

Recently it has been shown that the use of $\mathrm{TiO}_{2}$ can be extended to photocathodes as well as photoanodes. Andoshe et $a l .{ }^{88)}$ fabricated a photocathode with a heterojunction of $\mathrm{p}$ $\mathrm{Si}$ and $\mathrm{TiO}_{2}$ nanorod thin film. For the heterogeneous nucleation of $\mathrm{TiO}_{2}$ nanorods during hydrothermal synthesis, a 5 nm thick seed layer of the $\mathrm{TiO}_{2}$ film was deposited on $\mathrm{p}$-Si. Subsequently, $\mathrm{TiO}_{2}$ nanorods were hydrothermally grown on a seed layer of deposited p-Si substrate at $180-220^{\circ} \mathrm{C}$ for $0.5-2 \mathrm{~h}$. The solution for the hydrothermal process contained $25 \mathrm{~mL}$ of DI water, $25 \mathrm{~mL}$ of concentrated $\mathrm{HCl}$ and $0.8 \mathrm{~mL}$ of TBT. As shown in Fig. 10(a), the $\mathrm{TiO}_{2}$ nanorod/pSi photocathode exhibits a matt black color. As illustrated in Fig. 10(b)-(h), a gradual change in nanorod density along the vertical direction causes a steady change of refractive index that restricts total reflection. $\mathrm{TiO}_{2}$ has the additional role of passivating $\mathrm{p}$-Si from corrosion. Likewise, $\mathrm{TiO}_{2}$ exhibits a potential for heterojunction, passivation, and interface modulation materials.

\subsection{Photocathodes}

Despite significant efforts over the past decades to develop new photocathode materials for solar hydrogen production via water splitting, there are only a few metal oxide based photocathodes, such as copper-based oxides, that can meet the requirements for commercially viable solar water splitting. ${ }^{8,94-95)}$ Two long-standing bottlenecks for metal oxide photocathodes are sensitivity to photocorrosion during the hydrogen production process and low quantum efficiencies. Here, we review recent developments using metal oxidebased photocathodes synthesized by a solution process for efficient and stable water splitting.

\subsubsection{Cuprous oxide $\left(\mathrm{Cu}_{2} \mathrm{O}\right)$ and Copper oxide $(\mathrm{CuO})$}

$\mathrm{Cu}_{2} \mathrm{O}$ and $\mathrm{CuO}$ are the most representative p-type binary oxides that have been introduced for use in solar water splitting. In addition to their favorable band gap energies that allow for the utilization of visible light, the low cost, earth abundance, and non-toxicity of $\mathrm{Cu}$ are additional advantages for developing $\mathrm{Cu}$-based photoelectrodes. ${ }^{94)}$

$\mathrm{Cu}_{2} \mathrm{O}$, with a direct band gap of $2.0 \mathrm{eV}$, is an attractive oxide for solar water reduction, thus it is possible to theoretically reach a photocurrent of $14.7 \mathrm{~mA} / \mathrm{cm}^{2}$ and a solar to hydrogen efficiency of $18 \%$. The major limitation of $\mathrm{Cu}_{2} \mathrm{O}$ is photocorrosion (e.g., $\mathrm{Cu}_{2} \mathrm{O}+2 \mathrm{H}^{+}+2 \mathrm{e}^{-} \rightarrow 2 \mathrm{Cu}+\mathrm{H}_{2} \mathrm{O}$ ). ${ }^{96)}$ Paracchino et $a{ }^{97)}$ successfully synthesized $\mathrm{Cu}_{2} \mathrm{O}$ films by using electrochemical deposition, which was produced by cathodic reduction of $\mathrm{Cu}^{2+}$ ions in an aqueous alkaline $\mathrm{pH}$ 12) solution. $\mathrm{Cu}_{2} \mathrm{O}$ grains were covered with metal oxide protective layers $\left[5 \times\left(4 \mathrm{~nm} \mathrm{ZnO} / 0.17 \mathrm{~nm} \mathrm{Al}_{2} \mathrm{O}_{3}\right) / 11 \mathrm{~nm} \mathrm{TiO}_{2}\right]$ via atomic layer deposition (ALD), and finally coated with Pt nanoparticles, resulting in outstanding film quality when coated by ALD. Significantly, the protected $\mathrm{Cu}_{2} \mathrm{O}$ photocathode exhibited substantially improved photoactivity and stability. The surface-protected $\mathrm{Cu}_{2} \mathrm{O}$ achieved a photocurrent density of $-7.6 \mathrm{~mA} \mathrm{~cm}{ }^{-2}$ under AM 1.5 illumination; furthermore, the protected electrodes remained photoactive after $1 \mathrm{~h}$ of testing and the measured Faradaic efficiency was close to $100 \%$.

Yang et al. ${ }^{95)}$ demonstrated a $\mathrm{Cu}_{2} \mathrm{O} / \mathrm{CuO}$ bilayer composite synthesized by a facile method that involved electrodeposition and a subsequent thermal oxidation, as shown in Fig. 11(a)-(d). This strategy of combining electrodeposition and thermal oxidation provides an easy, low cost, and scalable strategy to prepare $\mathrm{Cu}_{2} \mathrm{O} / \mathrm{CuO}$ heterogeneous photocath- 

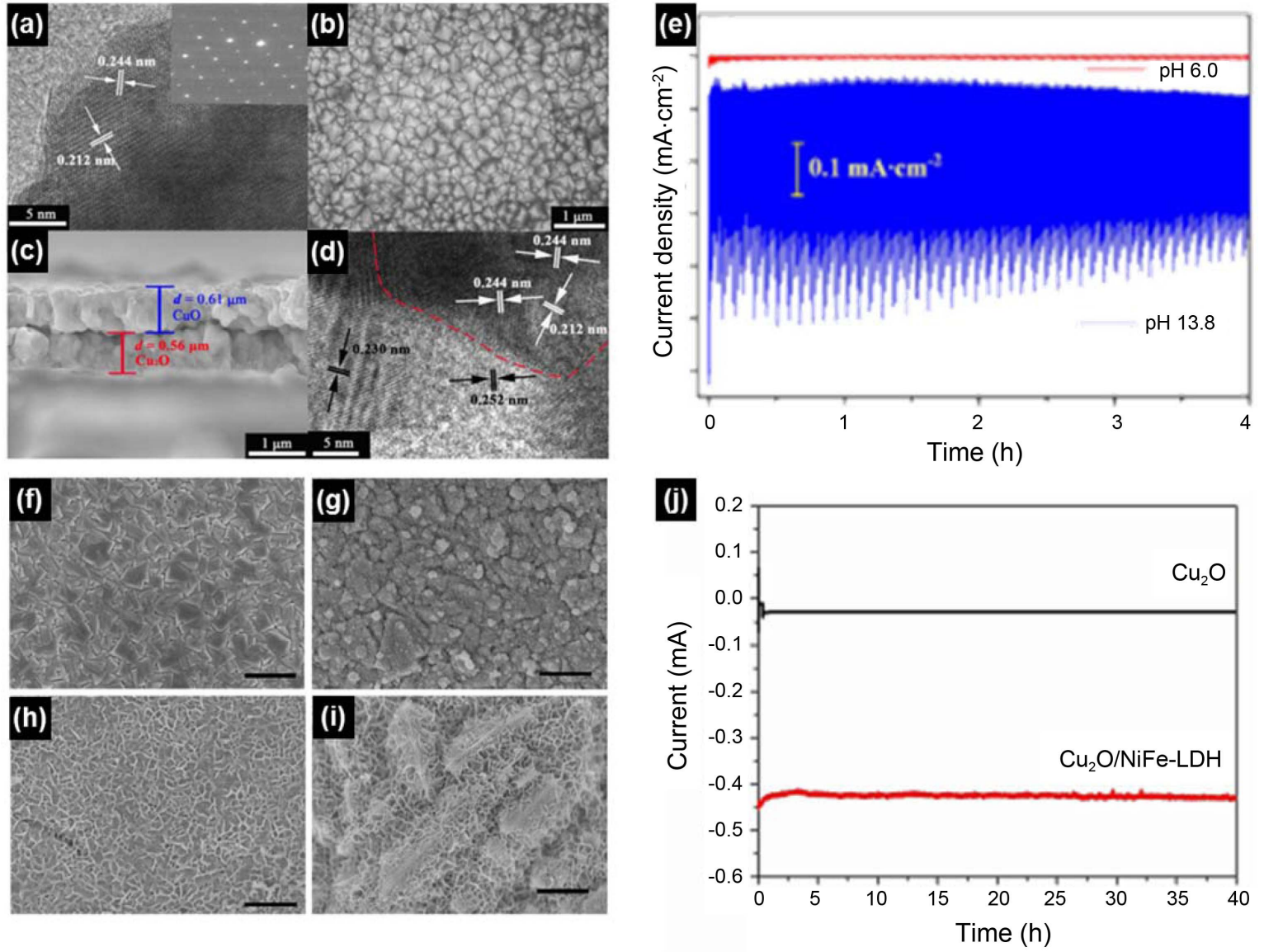

Fig. 11. (a) HRTEM image and SAED pattern (inset) of $\mathrm{Cu}_{2} \mathrm{O}$. (b) Top view and (c) cross-section view SEM images and (d) HRTEM image of $\mathrm{Cu}_{2} \mathrm{O} / \mathrm{CuO}$ bilayered composite. (e) Stability of $\mathrm{Cu}_{2} \mathrm{O} / \mathrm{CuO}$ bilayered composite with different $\mathrm{pH}$ values at $0.76 \mathrm{~V}$ vs. RHE. Adapted with permission from Ref 95. (f)-(i) SEM images of $\mathrm{Cu}_{2} \mathrm{O} / \mathrm{NiFe}-\mathrm{LDH}$ with different electrodeposition times from 20 to 300 s. (j) Stability of $\mathrm{Cu}_{2} \mathrm{O}$ and $\mathrm{Cu}_{2} \mathrm{O} / \mathrm{NiFe}-\mathrm{LDH}$ at $-0.2 \mathrm{~V}$ vs $\mathrm{Ag} / \mathrm{AgCl}$. Adapted with permission from Ref 94 .

odes for $\mathrm{HER}$. The $\mathrm{Cu}_{2} \mathrm{O} / \mathrm{CuO}$ photocathode exhibited significantly high photoactivity and good photostability toward HER, especially at high potentials in alkaline solution. The photocurrent density for HER was $3.15 \mathrm{~mA} / \mathrm{cm}^{2}$ at a potential of $0.40 \mathrm{~V}$ vs. RHE, which was one of the highest reported values at the same potential on copper-oxide-based photocathodes. Good photostability was seen during the $4 \mathrm{~h}$ measurements.

Qi et $a l .^{94)}$ introduced NiFe-layered double hydroxide (NiFe-LDHs) overlayers as co-catalyst on $\mathrm{Cu}_{2} \mathrm{O}$ electrodes via electrodeposition and studied their PEC behavior, as shown in Fig. 11(f)-(j). The electrodeposition enabled the synthesis of uniformly-anchored NiFe-LDH layered nanoplates onto the $\mathrm{Cu}_{2} \mathrm{O}$ surface. The resulting $\mathrm{Cu}_{2} \mathrm{O} / \mathrm{NiFe}$ LDH exhibited a remarkable 7-fold enhancement of photocurrent density under an applied voltage as low as $-0.2 \mathrm{~V}$ vs. $\mathrm{Ag} / \mathrm{AgCl}$. Also, long-term photostability tests revealed that $\mathrm{Cu}_{2} \mathrm{O} / \mathrm{NiFe}-\mathrm{LDH}$ photocathodes showed no photocurrent loss after $40 \mathrm{~h}$ of operation under light at $-0.2 \mathrm{~V}$ vs $\mathrm{Ag} /$ $\mathrm{AgCl}$ low bias condition, which makes $\mathrm{Cu}_{2} \mathrm{O} / \mathrm{NiFe}-\mathrm{LDH}$ photocathode a good candidate for low bias PEC water splitting.
$\mathrm{CuO}$ is another well-known photocathode with an indirect band gap of $1.2-1.8 \mathrm{eV}$. Due to its smaller band gap, it is possible to achieve a higher photocurrent than with $\mathrm{Cu}_{2} \mathrm{O}$, but $\mathrm{CuO}$ has received less attention than $\mathrm{Cu}_{2} \mathrm{O}$ for use as a photocathode in solar water splitting. This lack of attention is probably because of uncertainty as to whether the photoexcited electrons in $\mathrm{CuO}$ could reduce water to $\mathrm{H}_{2}$ (the conduction band minimum of $\mathrm{CuO}$ is reported to be between 0 and $-0.2 \mathrm{~V}$ vs RHE, which is more positive than that of $\left.\mathrm{Cu}_{2} \mathrm{O}\right){ }^{98)}$ Also, photocorrosion of $\mathrm{CuO}$ is another limiting factor for use in PEC water splitting. Recent studies showed suppressed photocorrosion of $\mathrm{CuO} .^{98-99)}$

Cardiel et al. ${ }^{100)}$ developed novel electrochemical synthesis methods to produce copper hydroxyl double salt (Cu-HDS) films with four different intercalated anions $\left(\mathrm{NO}^{3-}, \mathrm{SO}_{4}{ }^{2-}\right.$, $\mathrm{Cl}^{-}$, and dodecyl sulfate) as pure crystalline films, deposited as $\left(\mathrm{Cu}_{2} \mathrm{NO}_{3}(\mathrm{OH})_{3}, \mathrm{Cu}_{4} \mathrm{SO}_{4}(\mathrm{OH})_{6}, \mathrm{Cu}_{2} \mathrm{Cl}(\mathrm{OH})_{3}\right.$, and $\left.\mathrm{Cu}_{2} \mathrm{DS}(\mathrm{OH})_{3}\right)$, as shown in Fig. 12. These methods are based on p-benzoquinone reduction, which increases the local $\mathrm{pH}$ at the working electrode and triggers the precipitation of $\mathrm{Cu}^{2+}$ and appropriate anions as $\mathrm{Cu}-\mathrm{HDS}$ films on the working elec- 

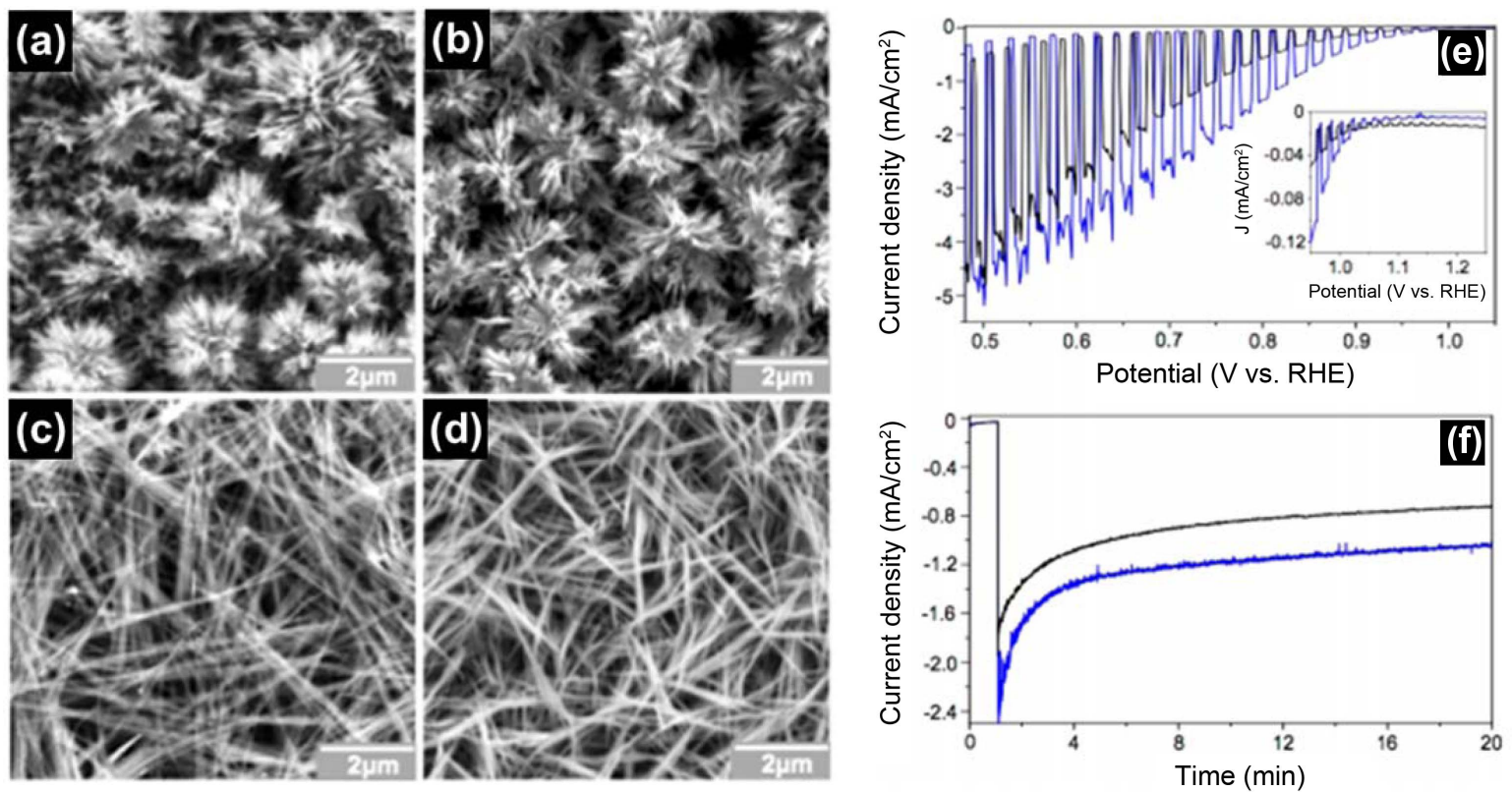

Fig. 12. SEM images of various copper oxide films originating from $\mathrm{Cu}-\mathrm{HDS} / \mathrm{SO}_{4}{ }^{2-}$ films; (a) After soaking in $\mathrm{pH} 12 \mathrm{solution}$ at $60^{\circ} \mathrm{C}$ for $2 \mathrm{~h}(\mathrm{CuO} \mathrm{I})$ and (b) after heat treatment of (a) at $500^{\circ} \mathrm{C}$ for $3 \mathrm{~h}(\mathrm{CuO} \mathrm{II})$. (c) After immersion in $1 \mathrm{M} \mathrm{NaOH}$ for $15 \mathrm{~s}$ and $(\mathrm{d})$ after heat treatment of (c) at $500^{\circ} \mathrm{C}$ for $3 \mathrm{~h} .(\mathrm{CuO}$ III) (e) LSV curve of $\mathrm{CuO}$ I (red line), CuO II (blue line) and $\mathrm{Cu}$ III (black line) under AM 1.5G $\left(100 \mathrm{MW} / \mathrm{cm}^{2}\right)$ illumination with chopped light condition. (f) Plot of current density vs. time at $0.7 \mathrm{~V}$ vs. RHE for $\mathrm{CuO}$ II (blue line) and $\mathrm{CuO}$ III (black line) under AM 1.5G (100 $\left.\mathrm{MW} / \mathrm{cm}^{2}\right)$ illumination. Adapted with permission from Ref 100.

trode. The resulting $\mathrm{Cu}$-HDS films could be converted to crystalline $\mathrm{Cu}(\mathrm{OH})_{2}$ and $\mathrm{CuO}$ films by immersing them in basic solutions. The $\mathrm{CuO}$ films prepared from $\mathrm{Cu}$-HDS films have unique low-dimensional nanostructures, creating high surface areas that cannot be obtained by direct deposition of
$\mathrm{CuO}$, which has a 3D atomic-level crystal structure, since $\mathrm{Cu}$-HDS films were composed of $2 \mathrm{D}$ crystals as a result of the atomic-level layered structure of HDS. The $\mathrm{CuO}$ films recorded great onset potential $(>1.0 \mathrm{~V}$ vs $\mathrm{RHE})$ very close to their flat band potential ( $1.2 \mathrm{~V}$ vs RHE), which shows
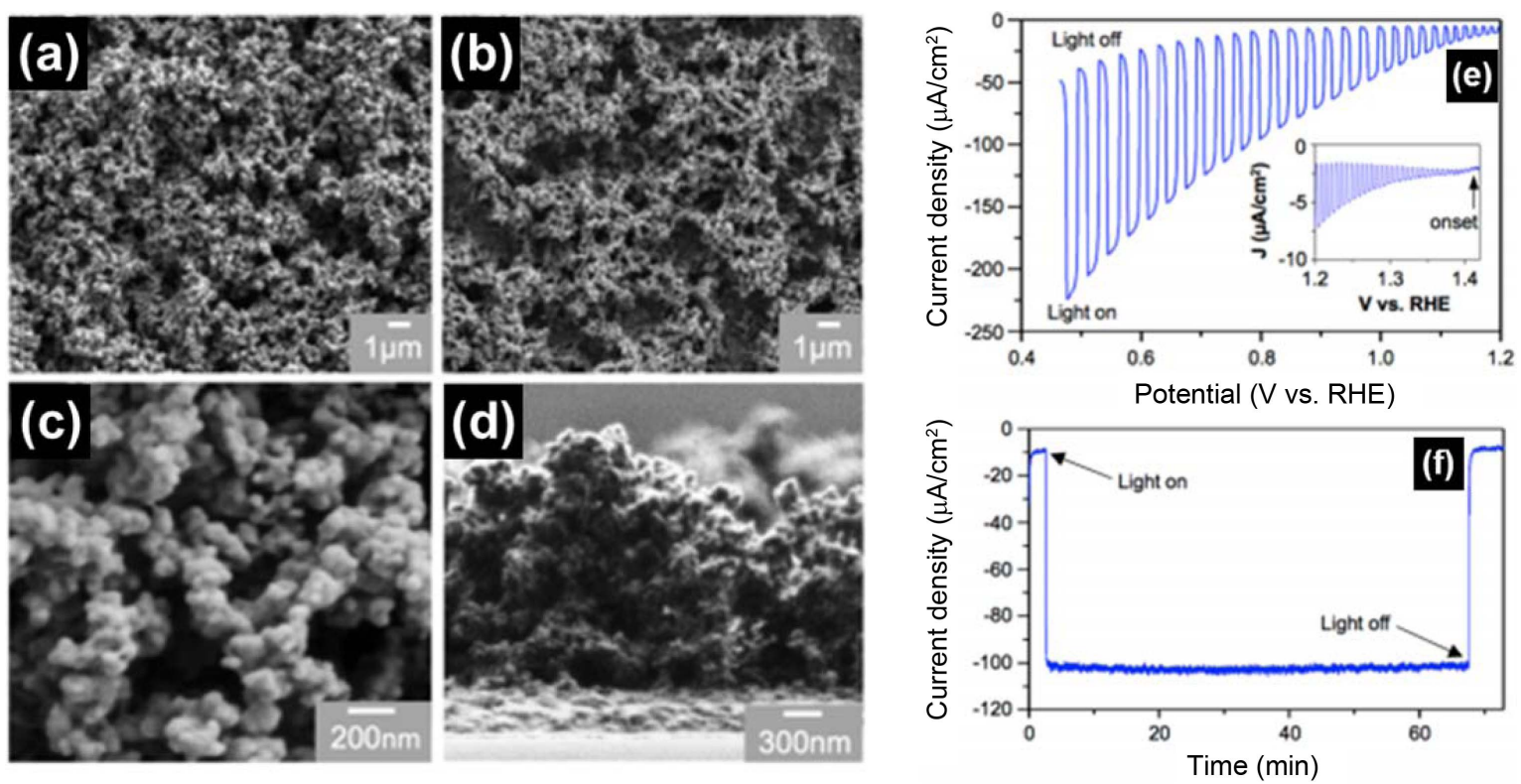

Fig. 13. SEM images of (a) an as-deposited La-Fe-O film with top view and (b-d) an annealed LaFeO3 film with top view and cross-section view, respectively. (e) LSV curve of $\mathrm{LaFeO}_{3}$ film under $\mathrm{AM} 1.5 \mathrm{G}\left(100 \mathrm{MW} / \mathrm{cm}^{2}\right)$ illumination with chopping light condition and (f) J-t plot of $\mathrm{LaFeO}_{3}$ film at $0.75 \mathrm{~V}$ vs. RHE of $\mathrm{LaFeO}_{3}$ under $\mathrm{AM} 1.5 \mathrm{G}\left(100 \mathrm{MW} / \mathrm{cm}^{2}\right)$ illumination. Adapted with permission from Ref 103. 
great promise for use as photocathodes in PEC cells for solar water splitting.

\subsubsection{Other Metal Oxides as Photocathode}

To date, metal oxides as photocathodes have been focused primarily on $\mathrm{Cu}$-based oxides such as $\mathrm{Cu}_{2} \mathrm{O}, \mathrm{CuO}, \mathrm{CuFeO}_{2}$ and $\mathrm{CuBi}_{2} \mathrm{O}_{4} \cdot{ }^{28,101-102)}$ However, the presence of copper in most p-type oxides is known to be a cause for photocorrosion, therefore these materials need a protection layer. Recent studies have searched for a breakthrough to solve the limitations of $\mathrm{Cu}$-based metal oxides as photocathodes.

Perovskite-type lanthanum iron oxide $\left(\mathrm{LaFeO}_{3}\right)$ is a ptype oxide that has several attractive characteristics such as an ideal band gap of $2.1 \mathrm{eV}$ and band edger positions for use in PEC water splitting. Wheeler et al. ${ }^{103)}$ reported nanoporous $\mathrm{LaFeO}_{3}$ prepared by electrochemical co-deposition of $\mathrm{La}(\mathrm{OH})_{3}$ and $\mathrm{Fe}(\mathrm{OH})_{2}$ via nitrate reduction, as shown in Fig. 13. The significant finding of this study is that, after $1 \mathrm{~h}$ of PEC measurement for water reduction at $0.5 \mathrm{~V}$ vs. RHE, there is a negligible portion of surface electrons being used for water reduction, and no sign of photocorrosion unlike $\mathrm{Cu}$-based metal oxides. This confirmed that $\mathrm{LaFeO}_{3}$ is a rare p-type oxide that does not suffer from photocorrosion. Therefore, the enhancement of the PEC performance of $\mathrm{LaFeO}_{3}$ can be expected with systematic doping studies and by combining it with a proper hydrogen catalyst.

\section{Perspective and Outlook}

Based on the previous discussion, we have reported the most recent progress of solution-based metal oxides for PEC water splitting. Even though metal oxide materials have substantial potential as photoelectrodes, there remain a number of challenges that need to be overcome. Poor electrical conductivity, limited light absorption, and photocorrosion are still the main drawbacks of most metal oxides when used as photoelectrodes for PEC water splitting. Thus, various strategies have been introduced to solve these limitations and improve the PEC performance of metal oxides. These strategies include the formation of nanostructures, band structure modification, introduction of plasmonic nanoparticles, the formation of heterostructures, and co-catalyst modification, in order to increase light absorption and enhance charge transfer. The following are some suggestions for future research directions along with their challenges, to improve PEC water splitting and possibly lead to breakthroughs.

The formation of nanostructures such as nanoparticles, nanotubes, nanorods, nanocorals, and nanotrees is a promising approach to enhance photoactivity. Morphology control provides an effective pathway for charge transport and to significantly suppress electron-hole recombination. Most of all, 3-dimensional (3D) net structures can not only provide more active sites for solar water splitting, but also facilitate charge transport and collection. The suggested solution processes have great potential to synthesize uniform 3D nanostructures and enable conformal deposition on various 1D nanostructures. The formation of type II heterojunctions has been recognized as an attractive route to promote efficient charge separation, which enlarges the interfacial area and improves optical absorption, thus it is crucial to find the best junction materials. Modification of band structure is a powerful approach to modify electronic structure and surface structure. The proper configuration and distribution of foreign dopants in semiconductor materials can optimize their electronic structures for efficient harvesting of sunlight. ${ }^{104,105)}$ Co-catalysts have played a critical role in the solar water splitting reaction, ${ }^{106)}$ such as reducing charge recombination, increasing reaction kinetics, and protecting materials from chemical corrosion, thus it is necessary to develop co-catalysts with cost-effective and superior properties. Plasmonic nanoparticles can increase the photocurrent density of metal oxides to exceed theoretical values, since three critical enhancement factors of plasmonics: hot electron injection, plasmonic resonance energy transfer, and scattering, can simultaneously operate. A further research field in PEC water splitting is to develop a suitable technology for large scale photoelectrode fabrication and cost-effective solar fuel production to compete with fossil fuel. All of the above strategies for developing efficient solar water splitting system can be satisfied by solution processes. Solution processes such as hydrothermal and electrodeposition facilitate the synthesis of uniform and 3D nanostructures by controlling parameters and enabling large-scale synthesis without restriction of electrode size. When considered together, it is clear that solution-based methods are a very promising pathway for cost-effective PEC cell fabrication systems.

In this article, we have reviewed recent progress in the field of nanostructured metal oxides synthesized by solution processes for PEC water splitting. We divided metal oxides into photoanodes and photocathodes. Unlike many impressive results that have been achieved in the use of metal oxides as photoanodes, research on metal oxides as photocathodes is markedly insufficient. In the future, it is necessary to find good candidates for photocathodes to make overall progress in PEC water splitting systems. Thus we believe that, besides improving the performance of existing metal oxide semiconductors, searching new metal oxide materials with highly efficient photocatalytic activity is also of crucial importance for PEC water splitting.

\section{Acknowledgments}

This research was supported by the Basic Science Research Program through the National Research Foundation of Korea (NRF) funded by the Ministry of Science, ICT \& Future Planning (2017R1A2B3009135).

\section{REFERENCES}

1. X. Li, J. Yu, J. Low, Y. Fang, J. Xiao, and X. Chen, "Engi- 
neering Heterogeneous Semiconductors for Solar Water Splitting," J. Mater. Chem. A, 3 [6] 2485-534 (2015).

2. J. Gan, X. Lu, and Y. Tong, "Towards Highly Efficient Photoanodes: Boosting Sunlight-Driven Semiconductor Nanomaterials for Water Oxidation," Nanoscale, 6 [13] 7142-64 (2014).

3. M. G. Lee, D. H. Kim, W. Sohn, C. W. Moon, H. Park, S. Lee, and H. W. Jang, "Conformally Coated $\mathrm{BiVO}_{4}$ Nanodots on Porosity-Controlled $\mathrm{WO}_{3}$ Nanorods as Highly Efficient Type II Heterojunction Photoanodes for Water Oxidation," Nano Energy, 28 250-60 (2016).

4. Z.-F. Huang, L. Pan, J.-J. Zou, X. Zhang, and L. Wang, "Nanostructured Bismuth Vanadate-Based Materials for Solar-Energy-Driven Water Oxidation: A Review on Recent Progress," Nanoscale, 6 [23] 14044-63 (2014).

5. M. G. Lee, C. W. Moon, H. Park, W. Sohn, S. B. Kang, S. Lee, K. J. Choi, and H. W. Jang, "Dominance of Plasmonic Resonant Energy Transfer over Direct Electron Transfer in Substantially Enhanced Water Oxidation Activity of $\mathrm{BiVO}_{4}$ by Shape-Controlled Au Nanoparticles," Small, 13 [37] 1701644 (2017)

6. C. Jiang, S. J. Moniz, A. Wang, T. Zhang, and J. Tang, "Photoelectrochemical Devices for Solar Water SplittingMaterials and Challenges," Chem. Soc. Rev., 46 [15] 464560 (2017).

7. T. Hisatomi and K. Domen, "Introductory Lecture: Sunlight-Driven Water Splitting and Carbon Dioxide Reduction by Heterogeneous Semiconductor Systems as Key Processes in Artificial Photosynthesis," Faraday Discuss., 198 11-35 (2017).

8. Y. Yang, S. Niu, D. Han, T. Liu, G. Wang, and Y. Li, "Progress in Developing Metal Oxide Nanomaterials for Photoelectrochemical Water Splitting," Adv. Energy Mater., 7 [19] 1700555 (2017).

9. I. D. Sharp, J. K. Cooper, F. M. Toma, and R. Buonsanti, "Bismuth Vanadate as a Platform for Accelerating Discovery and Development of Complex Transition-Metal Oxide Photoanodes," ACS Energy Lett., 2 [1] 139-50 (2016).

10. H. M. Chen, C. K. Chen, R.-S. Liu, L. Zhang, J. Zhang, and D. P. Wilkinson, "Nano-Architecture and Material Designs for Water Splitting Photoelectrodes," Chem. Soc. Rev., 41 [17] 5654-71 (2012).

11. H. Wang, L. Zhang, Z. Chen, J. Hu, S. Li, Z. Wang, J. Liu, and X. Wang, "Semiconductor Heterojunction Photocatalysts: Design, Construction, and Photocatalytic Performances," Chem. Soc. Rev., 43 [15] 5234-44 (2014).

12. M. G. Lee and H. W. Jang, "Photoactivities of Nanostructured $\alpha-\mathrm{Fe}_{2} \mathrm{O}_{3}$ Anodes Prepared by Pulsed Electrodeposition," J. Korean Ceram. Soc., 53 [4] 400-5 (2016).

13. J. Choi, J. T. Song, H. S. Jang, M.-J. Choi, D. M. Sim, S. Yim, H. Lim, Y. S. Jung, and J. Oh, "Interfacial BandEdge Engineered $\mathrm{TiO}_{2}$ Protection Layer on $\mathrm{Cu}_{2} \mathrm{O}$ Photocathodes for Efficient Water Reduction Reaction," Electron. Mater. Lett., 13 [1] 57-65 (2017).

14. K. S. Choi, H. S. Jang, C. M. McShane, C. G. Read, and J. A. Seabold, "Electrochemical Synthesis of Inorganic Polycrystalline Electrodes with Controlled Architectures," MRS Bull., 35 [10] 753-60 (2010).

15. X. B. Chen, S. H. Shen, L. J. Guo, and S. S. Mao, "Semi-
conductor-Based Photocatalytic Hydrogen Generation," Chem. Rev., 110 [11] 6503-70 (2010).

16. Y. Tachibana, L. Vayssieres, and J. R. Durrant, "Artificial Photosynthesis for Solar Water-Splitting," Nat. Photonics, 6 [8] 511-18 (2012).

17. K. Maeda and K. Domen, "Photocatalytic Water Splitting: Recent Progress and Future Challenges," J. Phys. Chem. Lett., 1 [18] 2655-61 (2010).

18. M. Vaseem, A. Umar, S. H. Kim, and Y.-B. Hahn, "LowTemperature Synthesis of Flower-Shaped CuO Nanostructures by Solution Process: Formation Mechanism and Structural Properties," J. Phys. Chem. C, 112 [15] 5729-35 (2008).

19. G. H. A. Therese and P. V. Kamath, "Electrochemical Synthesis of Metal Oxides and Hydroxides," Chem. Mater., 12 [5] 1195-204 (2000).

20. K. Byrappa and M. Yoshimura, Handbook of Hydrothermal Technology; William Andrew, 2012.

21. N. Liu, X. Chen, J. Zhang, and J. W. Schwank, "A Review on $\mathrm{TiO}_{2}$-based Nanotubes Synthesized via Hydrothermal Method: Formation Mechanism, Structure Modification, and Photocatalytic Applications," Catal. Today, 225 34-51 (2014).

22. C. J. Brinker and G. W. Scherer, Sol-Gel Science: The Physics and Chemistry of Sol-Gel Processing; Academic Press, 2013.

23. Y.-H. Kim, J.-S. Heo, T.-H. Kim, S. Park, M.-H. Yoon, J. Kim, M. S. Oh, G.-R. Yi, Y.-Y. Noh, and S. K. Park, "Flexible Metal-Oxide Devices Made by Room-Temperature Photochemical Activation of Sol-Gel Films," Nature, 489 [7414] 128-32 (2012).

24. S. Gorer and G. Hodes, "Quantum Size Effects in the Study of Chemical Solution Deposition Mechanisms of Semiconductor Films," J. Phys. Chem., 98 [20] 5338-46 (1994).

25. M. G. Walter, E. L. Warren, J. R. McKone, S. W. Boettcher, Q. X. Mi, E. A. Santori, and N. S. Lewis, "Solar Water Splitting Cells," Chem. Rev., 110 [11] 6446-73 (2010).

26. S. J. Moniz, S. A. Shevlin, D. J. Martin, Z.-X. Guo, and J. Tang, "Visible-Light Driven Heterojunction Photocatalysts for Water Splitting-a Critical Review," Energy Environ. Sci., 8 [3] 731-59 (2015).

27. C. X. Kronawitter, L. Vayssieres, S. Shen, L. Guo, D. A. Wheeler, J. Z. Zhang, B. R. Antoun, and S. S. Mao, "A Perspective on Solar-Driven Water Splitting with All-Oxide Hetero-Nanostructures," Energy Environ. Sci., 4 [10] 388999 (2011).

28. D. Kang, T. W. Kim, S. R. Kubota, A. C. Cardiel, H. G. Cha, and K. S. Choi, "Electrochemical Synthesis of Photoelectrodes and Catalysts for Use in Solar Water Splitting," Chem. Rev., 115 [23] 12839-87 (2015).

29. Z. W. Seh, J. Kibsgaard, C. F. Dickens, I. Chorkendorff, J. K. Nørskov, and T. F. Jaramillo, "Combining Theory and Experiment in Electrocatalysis: Insights into Materials Design," Science, 355 [6321] eaad4998 (2017).

30. T. Lindgren, L. Vayssieres, H. Wang, and S.-E. Lindquist, "Photo-Oxidation of Water at Hematite Electrodes," Chem. Phys. Nanostruct. Semicond., 83-110 (2003).

31. H. Tsubomura, N. Yamamoto, N. Matsuo, and Y. Okada, 
"The Visible Absorption Spectrum of Water," Proc. Jpn. Acad., Ser. B, 56 [7] 403-7 (1980).

32. K. L. Hardee and A. J. Bard, "Semiconductor Electrodes V. The Application of Chemically Vapor Deposited Iron Oxide Films to Photosensitized Electrolysis," J. Electrochem. Soc., 123 [7] 1024-26 (1976).

33. R. K. Quinn, R. Nasby, and R. Baughman, "Photoassisted Electrolysis of Water Using Single Crystal $\alpha-\mathrm{Fe}_{2} \mathrm{O}_{3}$ Anodes," Mater. Res. Bull., 11 [8] 1011-17 (1976).

34. J. H. Kennedy, M. Anderman, and R. Shinar, "Photoactivity of Polycrystalline $\alpha-\mathrm{Fe}_{2} \mathrm{O}_{3}$ Electrodes Doped with Group IVA Elements," J. Electrochem. Soc., 128 [11] 2371-73 (1981).

35. C. Sanchez, K. Sieber, and G. Somorjai, "The Photoelectrochemistry of Niobium Doped $\alpha-\mathrm{Fe}_{2} \mathrm{O}_{3}$, , J. Electroanal. Chem. Interfacial Electrochem., 252 [2] 269-90 (1988).

36. M. P. Dare-Edwards, J. B. Goodenough, A. Hamnett, and P. R. Trevellick, "Electrochemistry and Photoelectrochemistry of Iron (III) Oxide," J. Chem. Soc., Faraday Trans. 1, 79 [9] 2027-41 (1983).

37. J. H. Kennedy and K. W. Frese, "Photooxidation of Water at a-Fe $\mathrm{O}_{2} \mathrm{O}_{3}$ Electrodes," J. Electrochem. Soc., 125 [5] 70914 (1978)

38. A. G. Joly, J. R. Williams, S. A. Chambers, G. Xiong, W. P. Hess, and D. M. Laman, "Carrier Dynamics in $\alpha-\mathrm{Fe}_{2} \mathrm{O}_{3}$ (0001) Thin Films and Single Crystals Probed by Femtosecond Transient Absorption and Reflectivity," J. Appl. Phys., 99 [5] 053521 (2006).

39. G. Horowitz, "Capacitance-Voltage Measurements and Flat-Band Potential Determination on Zr-Doped $\alpha-\mathrm{Fe}_{2} \mathrm{O}_{3}$ Single-Crystal Electrodes," J. Electroanal. Chem. Interfacial Electrochem., 159 [2] 421-36 (1983).

40. W. W. Gärtner, "Depletion-Layer Photoeffects in Semiconductors," Phys. Rev., 116 [1] 84 (1959).

41. K. Itoh and J. O. M. Bockris, "Stacked Thin-Film Photoelectrode Using Iron Oxide,” J. Appl. Phys., 56 [3] 874-76 (1984).

42. K. Itoh and J. M. Bockris, "Thin Film Photoelectrochemistry: Iron Oxide," J. Electrochem. Soc., 131 [6] 1266-71 (1984).

43. R. Gardner, F. Sweett, and D. Tanner, "The Electrical Properties of Alpha Ferric Oxide-II.: Ferric Oxide of High Purity," J. Phys. Chem. Solids, 24 [10] 1183-96 (1963).

44. K. Sivula, R. Zboril, F. L. Formal, R. Robert, A. Weidenkaff, J. Tucek, J. Frydrych, and M. Gratzel, "Photoelectrochemical Water Splitting with Mesoporous Hematite Prepared by a Solution-Based Colloidal Approach," J. Am. Chem. Soc., 132 [21] 7436-44 (2010).

45. F. L. Souza, K. P. Lopes, P. A. Nascente, and E. R. Leite, "Nanostructured Hematite Thin Films Produced by SpinCoating Deposition Solution: Application in Water Splitting," Sol. Energy Mater. Sol. Cells, 93 [3] 362-68 (2009).

46. J. Brillet, M. Gratzel, and K. Sivula, "Decoupling Feature Size and Functionality in Solution-Processed, Porous Hematite Electrodes for Solar Water Splitting," Nano Lett., 10 [10] 4155-60 (2010).

47. J. Y. Kim, D. H. Youn, K. Kang, and J. S. Lee, "Highly Conformal Deposition of an Ultrathin $\mathrm{FeOOH}$ Layer on a Hematite Nanostructure for Efficient Solar Water Split- ting," Angew. Chem., Int. Ed., 55 [36] 10854-58 (2016).

48. T. W. Kim and K.-S. Choi, "Nanoporous BiVO ${ }_{4}$ Photoanodes with Dual-Layer Oxygen Evolution Catalysts for Solar Water Splitting," Science, 343 [6174] 1245026 (2014).

49. F. E. Osterloh, "Inorganic Nanostructures for Photoelectrochemical and Photocatalytic Water Splitting," Chem. Soc. Rev., 42 [6] 2294-320 (2013).

50. G. Xi and J. Ye, "Synthesis of Bismuth Vanadate Nanoplates with Exposed $\{001\}$ Facets and Enhanced VisibleLight Photocatalytic Properties," Chem. Commun., 46 [11] 1893-95 (2010).

51. K. J. McDonald and K.-S. Choi, "A New Electrochemical Synthesis Route for a BiOI Electrode and its Conversion to a Highly Efficient Porous $\mathrm{BiVO}_{4}$ Photoanode for Solar Water Oxidation," Energy Environ. Sci., 5 [9] 8553-57 (2012)

52. J. A. Seabold and K.-S. Choi, "Efficient and Stable PhotoOxidation of Water by a Bismuth Vanadate Photoanode Coupled with an Iron Oxyhydroxide Oxygen Evolution Catalyst," J. Am. Chem. Soc., 134 [4] 2186-92 (2012).

53. B. Jin, E. Jung, M. Ma, S. Kim, K. Zhang, J. I. Kim, Y. Son, and J. H. Park, "Solution-Processed Yolk-ShellShaped $\mathrm{WO}_{3} / \mathrm{BiVO}_{4}$ Heterojunction Photoelectrode for Efficient Solar Water Splitting," J. Mater. Chem. A, 2018 [6] 2585-92 (2018).

54. Y. Pihosh, I. Turkevych, K. Mawatari, J. Uemura, Y. Kazoe, S. Kosar, K. Makita, T. Sugaya, T. Matsui, and D. Fujita, "Photocatalytic Generation of Hydrogen by CoreShell $\mathrm{WO}_{3} / \mathrm{BiVO}_{4}$ Nanorods with Ultimate Water Splitting Efficiency," Sci. Rep., 511141 (2015).

55. A. Fujishima, T. N. Rao, and D. A. Tryk, "Titanium Dioxide Photocatalysis," J. Photochem. Photobiol., C, 1 [1] 1-21 (2000)

56. U. Diebold, "The Surface Science of Titanium Dioxide," Surf. Sci. Rep., 48 [5-8] 53-229 (2003).

57. X. Chen and S. S. Mao, "Titanium Dioxide Nanomaterials: Synthesis, Properties, Modifications, and Applications," Chem. Rev., 107 [7] 2891-959 (2007).

58. M. Grätzel, "A Low-Cost, High-Efficiency Solar Cell Based on Dye-Sensitized Colloidal Titanium Dioxide Films," Nature, 353 737-40 (1991).

59. Y. Matsumoto, M. Murakami, T. Shono, T. Hasegawa, T. Fukumura, M. Kawasaki, P. Ahmet, T. Chikyow, S.-Y. Koshihara, and H. Koinuma, "Room-Temperature Ferromagnetism in Transparent Transition Metal-Doped Titanium Dioxide," Science, 291 [5505] 854-56 (2001).

60. A. Fujishima and K. Honda, "Electrochemical Photolysis of Water at a Semiconductor Electrode," Nature, 238 [5358] 37-8 (1972).

61. O. Carp, C. L. Huisman, and A. Reller, "Photoinduced Reactivity of Titanium Dioxide," Prog. Solid State Chem., 32 [1-2] 33-177 (2004).

62. X. Chen, L. Liu, Y. Y. Peter, and S. S. Mao, "Increasing Solar Absorption for Photocatalysis with Black Hydrogenated Titanium Dioxide Nanocrystals," Science, 331 [6018] 746-50 (2011).

63. T. Umebayashi, T. Yamaki, H. Itoh, and K. Asai, "Band Gap Narrowing of Titanium Dioxide by Sulfur Doping," Appl. Phys. Lett., 81 [3] 454-56 (2002). 
64. R. I. Bickley, T. Gonzalez-Carreno, J. S. Lees, L. Palmisano, and R. J. Tilley, "A Structural Investigation of Titanium Dioxide Photocatalysts," J. Solid State Chem., 92 [1] 178-90 (1991).

65. M. Pelaez, N. T. Nolan, S. C. Pillai, M. K. Seery, P. Falaras, A. G. Kontos, P. S. Dunlop, J. W. Hamilton, J. A. Byrne, and K. O'shea, "A Review on the Visible Light Active Titanium Dioxide Photocatalysts for Environmental Applications," Appl. Catal., B, 125 331-49 (2012).

66. Y. Bessekhouad, D. Robert, and J. V. Weber, "Synthesis of Photocatalytic $\mathrm{TiO}_{2}$ Nanoparticles: Optimization of the Preparation Conditions," J. Photochem. Photobiol., A, 157 [1] 47-53 (2003).

67. K. D. Kim and H. T. Kim, "Synthesis of $\mathrm{TiO}_{2}$ Nanoparticles by Hydrolysis of TEOT and Decrease of Particle Size Using a Two-Stage Mixed Method," Powder Technolo., 119 [2-3] 164-72 (2001).

68. I. Kuznetsova, V. Blaskov, I. Stambolova, L. Znaidi, and A. Kanaev, " $\mathrm{TiO}_{2}$ Pure Phase Brookite with Preferred Orientation, Synthesized as a Spin-Coated Film," Mater. Lett., 59 [29-30] 3820-23 (2005).

69. J. H. Lee and Y. S. Yang, "Effect of HCl Concentration and Reaction Time on the Change in the Crystalline State of $\mathrm{TiO}_{2}$ Prepared from Aqueous $\mathrm{TiCl}_{4}$ Solution by Precipitation," J. Eur. Ceram. Soc., 25 [16] 3573-78 (2005).

70. P. Liu, J. Bandara, Y. Lin, D. Elgin, L. F. Allard, and Y.-P. Sun, "Formation of Nanocrystalline Titanium Dioxide in Perfluorinated Ionomer Membrane," Langmuir, 18 [26] 10398-401 (2002).

71. S. Seifried, M. Winterer, and H. Hahn, "Nanocrystalline Titania Films and Particles by Chemical Vapor Synthesis," Chem. Vap. Deposition, 6 [5] 239-44 (2000).

72. J. Ayllon, A. Figueras, S. Garelik, L. Spirkova, J. Durand, and L. Cot, "Preparation of $\mathrm{TiO}_{2}$ Powder Using Titanium Tetraisopropoxide Decomposition in a Plasma Enhanced Chemical Vapor Deposition (PECVD) Reactor," J. Mater. Sci. Lett., 18 [16] 1319-21 (1999).

73. H. D. Jang and S.-K. Kim, "Controlled Synthesis of Titanium Dioxide Nanoparticles in a Modified Diffusion Flame Reactor," Mater. Res. Bull., 36 [3-4] 627-37 (2001).

74. J.-J. $\mathrm{Wu}$ and C.-C. Yu, "Aligned $\mathrm{TiO}_{2}$ Nanorods and Nanowalls," J. Phys. Chem. B, 108 [11] 3377-79 (2004).

75. J.-M. Wu, H. C. Shih, and W.-T. Wu, "Electron Field Emission from Single Crystalline $\mathrm{TiO}_{2}$ Nanowires Prepared by Thermal Evaporation," Chem. Phys. Lett., 413 [4-6] 490-94 (2005).

76. J.-M. Wu, H. C. Shih, W.-T. Wu, Y.-K. Tseng, and I.-C. Chen, "Thermal Evaporation Growth and the Luminescence Property of $\mathrm{TiO}_{2}$ Nanowires," J. Cryst. Growth, 281 [2-4] 384-90 (2005).

77. B. Xiang, Y. Zhang, Z. Wang, X. Luo, Y. Zhu, H. Zhang, and D. Yu, "Field-Emission Properties of $\mathrm{TiO}_{2}$ Nanowire Arrays," J. Phys. D: Appl. Phys., 38 [8] 1152 (2005).

78. M. Ayers and A. Hunt, "Titanium Oxide Aerogels Prepared from Titanium Metal and Hydrogen Peroxide," Mater. Lett., 34 [3-6] 290-93 (1998).

79. L. Campbell, B. Na, and E. Ko, "Synthesis and Characterization of Titania Aerogels," Chem. Mater., 4 [6] 1329-33 (1992).
80. S.-S. Hong, M. S. Lee, S. S. Park, and G.-D. Lee, "Synthesis of Nanosized $\mathrm{TiO}_{2} / \mathrm{SiO}_{2}$ Particles in the Microemulsion and their Photocatalytic Activity on the Decomposition of p-Nitrophenol," Catal. Today, 87 [1-4] 99-105 (2003).

81. K. D. Kim, S. H. Kim, and H. T. Kim, "Applying the Taguchi Method to the Optimization for the Synthesis of $\mathrm{TiO}_{2}$ Nanoparticles by Hydrolysis of TEOT in Micelles," Colloids Surf., A, 254 [1-3] 99-105 (2005).

82. A. Ali and W.-C. Oh, "Preparation of $\mathrm{Ag}_{2} \mathrm{Se}$-Graphene$\mathrm{TiO}_{2}$ Nanocomposite and its Photocatalytic Degradation (Rh B)," J. Korean Ceram. Soc., 54 [5] 388-94 (2017).

83. Z. Li, H. Yang, F. Wu, J. Fu, L. Wang, and W. Yang, "Single-Crystalline Self-Branched Anatase Titania Nanowires for Dye-Sensitized Solar Cells," Electron. Mater. Lett., 13 [2] 174-78 (2017).

84. Y. Lin, G. Wu, X. Yuan, T. Xie, and L. Zhang, "Fabrication and Optical Properties of $\mathrm{TiO}_{2}$ Nanowire Arrays Made by Sol-Gel Electrophoresis Deposition into Anodic Alumina Membranes," J. Phys.: Condens. Matter., 15 [17] 2917-22 (2003).

85. S. Lee, C. Jeon, and Y. Park, "Fabrication of $\mathrm{TiO}_{2}$ Tubules by Template Synthesis and Hydrolysis with Water Vapor," Chem. Mater., 16 [22] 4292-95 (2004).

86. S. Liu, L. Gan, L. Liu, W. Zhang, and H. Zeng, "Synthesis of Single-Crystalline $\mathrm{TiO}_{2}$ Nanotubes," Chem. Mater., 14 [3] 1391-97 (2002).

87. J. Qiu, W. Yu, X. Gao, and X. Li, "Sol-Gel Assisted ZnO Nanorod Array Template to Synthesize $\mathrm{TiO}_{2}$ Nanotube Arrays," Nanotechnology, 17 [18] 4695 (2006).

88. D. M. Andoshe, S. Choi, Y.-S. Shim, S. H. Lee, Y. Kim, C. W. Moon, D. H. Kim, S. Y. Lee, T. Kim, and H. K. Park, "A Wafer-Scale Antireflective Protection Layer of SolutionProcessed $\mathrm{TiO}_{2}$ Nanorods for High Performance SiliconBased Water Splitting Photocathodes," J. Mater. Chem. A, 4 [24] 9477-85 (2016).

89. Y. Chung, W. Lo, and G. Somorjai, "Low Energy Electron Diffraction and Electron Spectroscopy Studies of the Clean (110) and (100) Titanium Dioxide (Rutile) Crystal Surfaces," Surf. Sci., 64 [2] 588-602 (1977).

90. M. Ramamoorthy, D. Vanderbilt, and R. King-Smith, "First-Principles Calculations of the Energetics of Stoichiometric $\mathrm{TiO}_{2}$ Surfaces," Phys. Rev. B, 49 [23] 16721 (1994)

91. A. Barnard and L. Curtiss, "Prediction of $\mathrm{TiO}_{2}$ Nanoparticle Phase and Shape Transitions Controlled by Surface Chemistry," Nano Lett., 5 [7] 1261-66 (2005).

92. I. S. Cho, Z. Chen, A. J. Forman, D. R. Kim, P. M. Rao, T. F. Jaramillo, and X. Zheng, "Branched $\mathrm{TiO}_{2}$ Nanorods for Photoelectrochemical Hydrogen Production," Nano Lett., 11 [11] 4978-84 (2011).

93. F. Su, T. Wang, R. Lv, J. Zhang, P. Zhang, J. Lu, and J. Gong, "Dendritic $\mathrm{Au} / \mathrm{TiO}_{2}$ Nanorod Arrays for VisibleLight Driven Photoelectrochemical Water splitting," Nanoscale, 5 [19] 9001-9 (2013).

94. H. Qi, J. Wolfe, D. Fichou, and Z. Chen, " $\mathrm{Cu}_{2} \mathrm{O}$ Photocathode for Low Bias Photoelectrochemical Water Splitting Enabled by NiFe-Layered Double Hydroxide Co-Catalyst," Sci. Rep., 630882 (2016).

95. Y. Yang, D. Xu, Q. Wu, and P. Diao, " $\mathrm{Cu}_{2} \mathrm{O} / \mathrm{CuO}$ Bilayered 
Composite as a High-Efficiency Photocathode for Photoelectrochemical Hydrogen Evolution Reaction," Sci. Rep., 635158 (2016).

96. H. Gerischer, "On the Stability of Semiconductor Electrodes against Photodecomposition," J. Electroanal. Chem. Interfacial Electrochem., 82 [1-2] 133-43 (1977).

97. A. Paracchino, V. Laporte, K. Sivula, M. Grätzel, E. Thimsen, "Highly Active Oxide Photocathode for Photoelectrochemical Water Reduction," Nat. Mater., 10 [6] 456 (2011).

98. S. Emin, F. Abdi, M. Fanetti, W. Peng, W. Smith, K. Sivula, B. Dam, and M. Valant, "A Novel Approach for the Preparation of Textured $\mathrm{CuO}$ Thin Films from Electrodeposited $\mathrm{CuCl}$ and CuBr," J. Electroanal. Chem., 717 243-49 (2014).

99. C.-Y. Chiang, Y. Shin, K. Aroh, and S. Ehrman, "Copper Oxide Photocathodes Prepared by a Solution Based Process," Int. J. Hydrogen Energy, 37 [10] 8232-39 (2012).

100. A. C. Cardiel, K. J. McDonald, and K.-S. Choi, "Electrochemical Growth of Copper Hydroxy Double Salt Films and Their Conversion to Nanostructured p-Type $\mathrm{CuO}$ Photocathodes," Langmuir, 33 [37] 9262-70 (2017).

101. C. G. Read, Y. Park, and K.-S. Choi, "Electrochemical Synthesis of p-type $\mathrm{CuFeO}_{2}$ Electrodes for Use in a Photoelectrochemical Cell," J. Phys. Chem. Lett., 3 [14] 1872-76 (2012).
102. N. T. Hahn, V. C. Holmberg, B. A. Korgel, and C. B. Mullins, "Electrochemical Synthesis and Characterization of p-CuBi $\mathrm{O}_{4}$ Thin Film Photocathodes," J. Phys. Chem. C, 116 [10] 6459-66 (2012).

103. G. P. Wheeler and K.-S. Choi, "Photoelectrochemical Properties and Stability of Nanoporous p-Type $\mathrm{LaFeO}_{3}$ Photoelectrodes Prepared by Electrodeposition," ACS Energy Lett., 2 [10] 2378-82 (2017).

104. J. Y. Kim, G. Magesh, D. H. Youn, J. W. Jang, J. Kubota, K. Domen, and J. S. Lee, "Single-Crystalline, Wormlike Hematite Photoanodes for Efficient Solar Water Splitting," Sci. Rep., 32681 (2013).

105. W. Cheng, J. He, Z. Sun, Y. Peng, T. Yao, Q. Liu, Y. Jiang, F. Hu, Z. Xie, B. He, and S. Wei, "Ni-Doped Overlayer Hematite Nanotube: A Highly Photoactive Architecture for Utilization of Visible Light," J. Phys. Chem. C, 116 [45] 24060-67 (2012).

106. J. M. Jeon, T. L. Kim, Y. S. Shim, Y. R. Choi, S. Lee, K. C. Kwon, S. H. Hong, Y. W. Kim, S. Y. Kim, M. Kim, and H. W. Jang, "Microscopic Evidence for Strong Interaction between Pd and Graphene Oxide that Results in MetalDecoration-Induced Reduction of Graphene Oxide," Adv. Mater., 29 [45] 1605929 (2017). 